\title{
Detection and Location of Earth Fault in MV Feeders Using Screen Earthing Current Measurements
}

\author{
Krzysztof Lowczowski ${ }^{1, *} \mathbb{D}$, Jozef Lorenc ${ }^{1}$, Jozef Zawodniak ${ }^{2}$ and Grzegorz Dombek ${ }^{1} \mathbb{D}$ \\ 1 Institute of Electric Power Engineering, Poznan University of Technology, Piotrowo 3A, 60965 Poznan, \\ Poland; jozef.lorenc@put.poznan.pl (J.L.); grzegorz.dombek@put.poznan.pl (G.D.) \\ 2 Department of Network Asset Management, Enea Operator, Strzeszynska 58, 60479 Poznan, Poland; \\ jozef.zawodniak@operator.enea.pl \\ * Correspondence: krzysztof.lowczowski@put.poznan.pl; Tel.: +48-61-665-2270
}

Received: 4 February 2020; Accepted: 8 March 2020; Published: 10 March 2020

\begin{abstract}
The paper analyzes the utilization of cable screen currents for earth fault identification and location. Attention is paid on cable and mixed feeders-cable and overhead lines. The principle of operation is based on utilization of 3 criterion values: Ratio of cable screen earthing current and zero sequence cable core current- $R F_{110 / 15}$, phase shift between cable screen earthing current and zero sequence cable core current $-\alpha$ and cable screen admittance defined as a ratio of cable screen earthing current and zero sequence voltage $-Y_{0 c s}$. Earth fault location is possible thanks to discovered relation between $R F_{110 / 15}$ and $\alpha$, whereas $Y_{0 c s}$ allows for reliable detection of earth faults. Detection and identification are very important because it allows to increase the reliability of supply-reduce downtime and number of consumers affected by the fault. The article presents a phase to ground fault current flow for different power system configurations. At the end solution, which improves location capabilities is proposed. The solution is analyzed in PSCAD software and verified by network experiment.
\end{abstract}

Keywords: cable screen; earthing system distribution feeder; mixed cable-overhead line; protection relay; fault location; fault detection

\section{Introduction}

Nowadays one can notice a tendency to increase the number of measuring equipment installed in power system networks. The topic is analyzed by different organizations i.e., CIGRE WG B3.44-Substation servicing and supervision, present and expected future use of mobile devices and sensors. It is however noted that similar trends are observed in different industries. In industrial applications, one can observe the tendency to install 4.0 generation sensors, whereas in the consumer electronics industry one can observe the tendency to install more and more IoT devices [1]. It is, however, necessary to underline that, increasing the number of sensors leads to an increase in the amount of data. If data is not utilized properly will have a negative impact on the cost of IT system connected with data transmission, processing, and storage [2]. In order to maximize the effectiveness of installed sensors, it is necessary to process data locally, particularly in the case of wireless sensors, which have a limited amount of energy [3]. One has considered a fact that data transmission is more energy-consuming process than local data analysis. The paper focuses on the utilization of cable screen currents of MV power cables. In previous papers, a few functionalities were proposed-utilization of cable screen currents for identification of cable screen erroneous connection and for identification of earth faults in cable lines $[4,5]$. Moreover, proof of concept regarding the identification of line affected by phase to ground fault was presented. The literature presents additional functions like the identification of cable sheath faults. The paper presents earth fault for different configurations 
of power lines, the criterion of phase to ground fault detection is elaborated and the methodology of identification line affected by the fault is presented. Identification of line type affected by the fault is important in order to increase the reliability of the supply of MV distribution systems by reducing the time of fault removal and blocking of operation of auto-reclose. Reduced number of unsuccessful auto-reclose operations, helps to reduce thermal and mechanical tensions, which lead to oxidation of connection surface and PD discharges [6]. Moreover, a reduced number of unsuccessful auto-reclose operations helps to increase the quality of supply since voltage transients and sags connected with fault occurrence are reduced [7]. One has to hover notice that not all faults at the MV side are seen on the LV side. Thermal and mechanical tensions resulting from unsuccessful AR operation can be reduced by PulseCloser technology [8]. One has to underline that overvoltages still exist and could damage insulation and therefore utilization of prosed solution or combination of both is recommended.

Analysis of phase to ground faults is important since approximately $70-80 \%$ of all faults are phase to ground faults i.e., $72 \%$ in Portuguese [9]. In the case of cable lines, approximately a few earth faults are observed per $100 \mathrm{~km}$, whereas in case of overhead lines a number of faults are in the range of 20/100 km [10].

The proposed method is developed for 3 phase 3 wire system with 1 neutral point grounding or isolated systems. Four wires network, multi-point grounded network and others require different methods of fault location and blocking of AR [11]. The presented criteria are not valid in multi-point grounded system since additional earthing points would create parallel paths for earth fault current flow. As a result of the parallel current flow paths, cable screen earthing current could be bigger than zero sequence cable core current. The effect could be compared to reverse capacitive current presented in paragraph simulation. An exception would be a few point earthed system i.e., 2, but only if the neutral earthing points would be outside the protected feeder. The schematic diagram of the proposed solutions is presented in Figure 1. The second paragraph presents a method of fault location in MV networks. The next paragraph presents a simulation model and describes relations important for fault location. Simulation results are confronted with the measurement taken in MV network during network experiments. One previous last chapter presents the algorithm of identification of line type affected by fault and branch as well as the system for ground fault identification. The summary presents the most important features of the system and presents the scope of future works. 


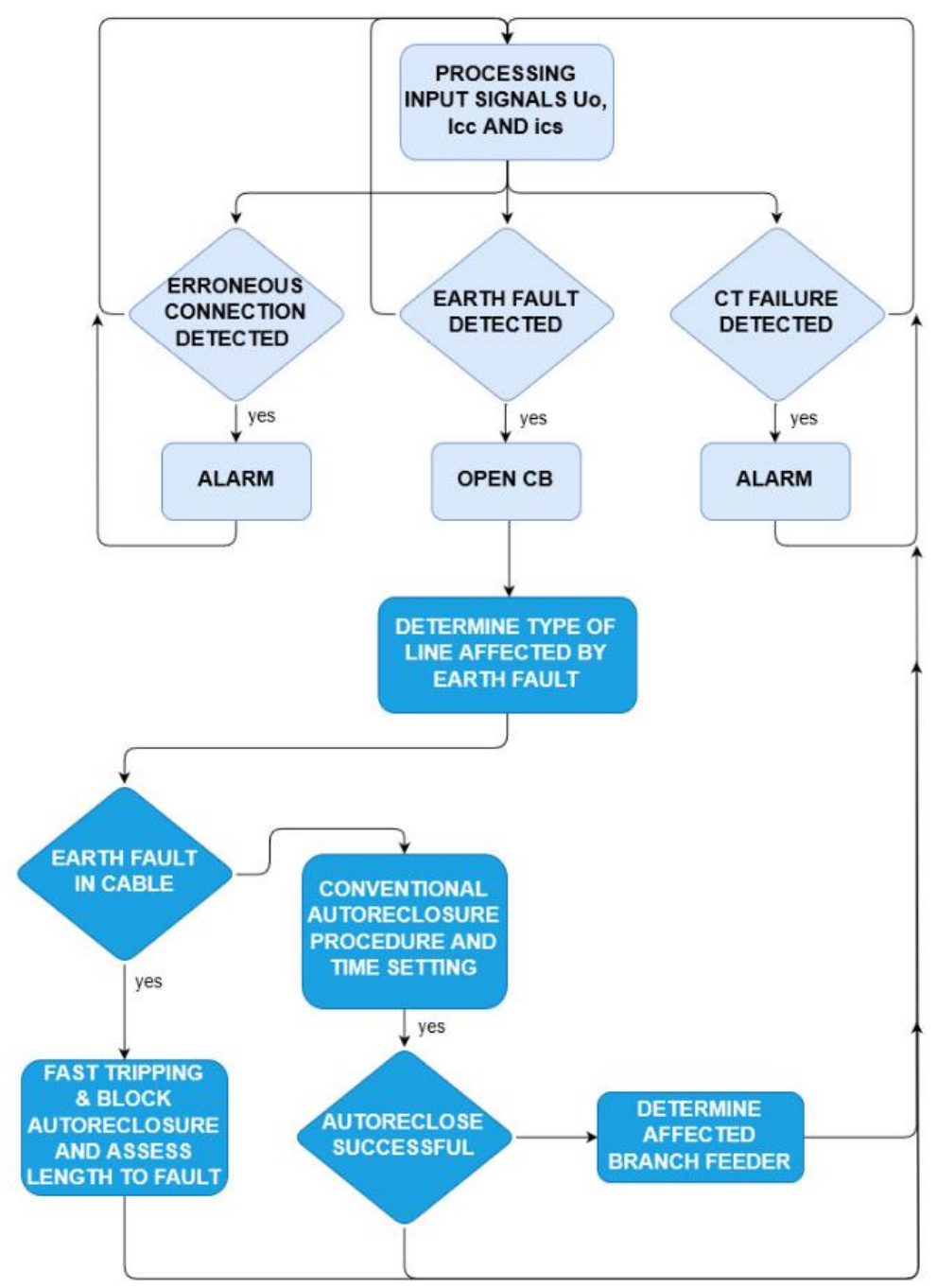

Figure 1. Schematic diagram of the developed system (the elements described in this study are marked in blue, and the elements in blue [5].

\section{Methods of Fault Localization}

The literature presents a big number of solutions developed for the identification of the line affected by the fault. The topic is important for power system distribution networks, industrial and railway networks [12]. Despite a big number of localization algorithms presented in the literature, only 2 methods are utilized on a bigger scale-fault current indicators and distance protection relay $[13,14]$. Effectiveness of distance protection relays under phase to ground fault is strongly limited-[15] claims that identification of $1 / 3$ of the feeder, which could be affected by the fault is a success. Distance protection is commonly used in HV and UHV lines and can identify the type of line affected by fault as long as the fault is not close to the point of line transition-cable to overhead [16]. Principle of operation of distance relay is presented in Figure 2-protection zone determined via impedance setting is marked with blue lines and feeder impedance, including branches, is marked with black color. Unfortunately measured fault impedance can be greatly shifted from the line impedance what is caused mostly by measuring and parameter errors as well as fault impedance-on MV level only resistance is considered. As a result, it is almost impossible to identify faulted branch. 


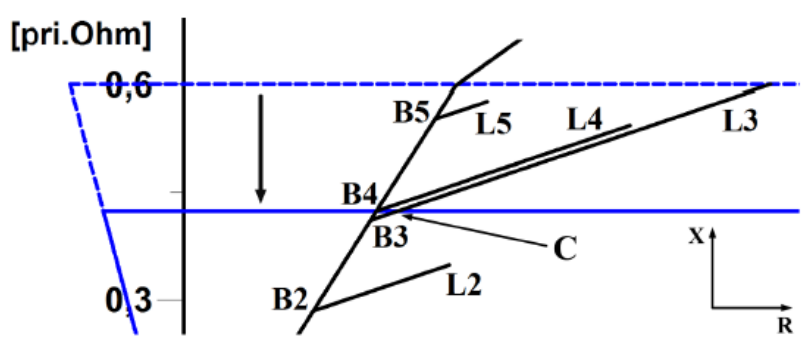

Figure 2. Characteristics of distance protection.

Utilization of distance relays in MV networks is connected with many problems i.e., difficulties with a determination of $k$ parameter Equation (1) required for proper calculation of impedance under phase to ground fault $[17,18]$. Effectiveness of distance relays is affected by load before fault occurrence, fault resistance, presence of additional power sources and others [19]. Due to many parameters affecting impedance measurement, there is uncertainty range of impedance measurement and distance to fault is only approximation.

$$
k=\frac{1}{3}\left(\underline{\underline{Z}}_{0}-1\right)
$$

where $\underline{Z}_{0}$ is zero sequence impedance, $\underline{Z}_{L}$ is positive sequence impedance.

The next alternative for the phase to ground fault location is the utilization of the phase shift between current transients recorded in different parts of networks [20]. The method is developed for cable lines, however, it is necessary to develop a method for cable-overhead lines. The disadvantage of the method is connected with the necessity of human interpretation of results and the necessity of high-quality devices_-recording signal with high sampling rate-in range of $\mathrm{MHz}$, which in turn increases the cost of the hardware. Automation of devices. Similar method-traveling waves method in 2 places uses additional processing methods-Teager Energy operator to identify the moment of traveling wave occurrence and wavelet Hilbert Huang transform for identification of transients [21]. Different methods of identification line type affected by fault are the installation of additional sensors along the protected feeder i.e., PD sensors on cable joints [22]. The concept, however, requires high investment costs and operational problems. The next identification concept is connected with an optimization algorithm for earth fault location. The method can be used in isolated and compensated mv networks. Unfortunately, the effectiveness of method operation depends on fault resistance and local energy sources. The effectiveness of identification is in the range of $80-95 \%$ [23]. Despite the presented method, harmonic based methods like Zon, Volna, ZVN, YC3, etc. or symmetrical component-based i.e., negative current are used [24,25].

Probably fault current indicator gained the biggest popularity in MV networks. The fault indicators indicate the area between indicators as an area under fault conditions. The disadvantage of the indicators is many complications and technical constraints i.e., installation and maintenance of the fault indicators [26,27]. Effectiveness of fault location can be increased if electrical signals are processed via advanced tools i.e., wavelet and correlation with other systems like geographic information system - GIS i.e., it is possible to claim that fault was created because of contact with tree, when trees are marked in GIS system one can reduce the area of search to place with trees i.e., forest [28]. It is also possible to analyze voltage sag type in order to identify fault reasons and localize the fault $[29,30]$.

Presented methods are based on phase currents measurements. The presented method is based on the screen current measurement. The literature presents information about the utilization of screen current measurement for identification of line, however, 3 phase cable screens currents and complex algorithms are necessary, whereas in the case of developed method only cable screen earthing current $-I_{0 c s}$ is needed [31]. Only 1 side current measurement is needed in the method and simple signal processing method what significantly reduces the cost of measuring equipment comparing to 
the other presented solutions. Due the specific operation-identification of the segment affected by the fault is compared with similar solutions-fault indicators and distance protection is compared in Table 1. Different fault location methods are compared in [32].

Table 1. Comparison of earth fault location methods in MV grids.

\begin{tabular}{|c|c|c|c|}
\hline Methods & Fault Current Indicator & Distance Protection & Proposed Solution \\
\hline Detection of $1 \mathrm{fg}$ faults & Yes & Yes & Yes \\
\hline $\begin{array}{l}\text { Detection of } 2 \mathrm{fg} \text { and } \\
\text { phase to phase faults }\end{array}$ & Yes & Yes & Yes $^{1}$ \\
\hline $\begin{array}{l}\text { Fault location } \\
\text { identification }\end{array}$ & $\begin{array}{l}\text { The section between } 2 \\
\text { indicators }{ }^{2}\end{array}$ & $\begin{array}{l}\text { The estimated location of } \\
\text { phase to phase faults }{ }^{3}\end{array}$ & $\begin{array}{l}\text { Estimated location to faults in } \\
\text { cable lines and identification } \\
\text { of line type affected by faults } 4\end{array}$ \\
\hline $\begin{array}{l}\text { Identification of branches } \\
\text { affected by faults }\end{array}$ & $\begin{array}{l}\text { Yes, if additional current } \\
\text { indicators are installed and } \\
\text { integrated with the fault } \\
\text { management system }{ }^{5}\end{array}$ & In exceptional cases ${ }^{6}$ & $\begin{array}{l}\text { Yes, if there are significant } \\
\text { differences in electric } \\
\text { parameters between lines }\end{array}$ \\
\hline $\begin{array}{l}\text { The complexity of } \\
\text { measuring system }\end{array}$ & $\begin{array}{l}\text { Very big - many measuring } \\
\text { systems }\end{array}$ & $\begin{array}{l}\text { Big - complex algorithm } \\
\text { and hardware } 7\end{array}$ & $\begin{array}{l}\text { Average - utilization of } \\
\text { additional current sensors for } \\
I_{0 c s} \text { measurement }\end{array}$ \\
\hline Advantages & $\begin{array}{l}\text { Possibility to install indicators } \\
\text { in convenient places }\end{array}$ & $\begin{array}{l}\text { Good operational } \\
\text { performance in case of } \\
\text { phase to phase faults }\end{array}$ & $\begin{array}{l}\text { Gives the possibility to use } 2 \\
\text { different time settings }\end{array}$ \\
\hline Operational issues & $\begin{array}{c}\text { Difficult installation and } \\
\text { maintenance actions in } \\
\text { different places. } \\
\text { Communication is required }\end{array}$ & $\begin{array}{l}\text { Difficult - expensive } \\
\text { protection relay tester is } \\
\text { required }{ }^{9}\end{array}$ & Average difficulty ${ }^{10}$ \\
\hline $\begin{array}{l}\text { Proper operation in case } \\
\text { of neutral point failure }\end{array}$ & No & No & Yes \\
\hline Auto reclose blocking & Possible ${ }^{11}$ & In exceptional cases ${ }^{12}$ & Possible \\
\hline
\end{tabular}

${ }^{1}$ According to preliminary investigation it is possible to detect ${ }^{2}$ phase to ground faults using cable screen earthing current. Due to complexity, the topic is excluded from the paper content. 2. The effectiveness of fault current indicators strongly depends on number of indicators used. Theoretically fault current indicators could be installed at every support structure of the overhead line. At the same time one has to notice that cost would increase greatly. ${ }^{3}$ The estimated location in case of an earth fault in distribution network is $1 / 3$ of the protected feeder. ${ }^{4}$ Detailed description in the following sections of the paper. ${ }^{5}$ From technical point of view earth fault current indicators can be adopted to any complex feeder. One has to underline that performance (unwanted trips or missing trips) of simple fault current indicators has often been questioned. ${ }^{6}$ In exceptional cases it is possible-if points on $R F_{110 / 15}=\mathrm{f}(\alpha)$ differ significantly, it is possible to indicate branch affected by fault (the principle is presented in paragraph 4 ). ${ }^{7}$ In case of conventional distance relays one can observe complex, sophisticated algorithms, which require fast hardware for real time control of 6 fault impedance loops. ${ }^{8}$ Communication failure can compromise the system. ${ }^{9}$ Verification of distance protection performance require a tester with 4 current and 4 voltage outputs. Additional training for utility employees responsible for testing is required. ${ }^{10}$ Detailed description and analysis is difficult what is presented in the paper. At the same time however one can notice that interpretation of method, development of model is relatively simple. It is believed that a few hours training would be sufficient to educate a new utility employee. ${ }^{11}$ If earth fault indicator is installed at the end of the cable lines. ${ }^{12}$ In exceptional cases-long overhead line and short cable line.

In the literature, much attention is paid on the analysis of local energy sources on protection relay [33]. Proposed solution work properly in active system networks with many additional power sources and new devices like fault current limiters (FCLs) etc. since zero-sequence current flow is not affected by Dy transformers and YYn transformers, ungrounded at MV side [34,35]. Local energy sources could affect zero-sequence current flow if YNyn transformer is used [36,37]. In such case local energy sources i.e., prosumers could have an impact on zero-sequence current flow. In most cases however prosumers have small power and as a result, the impact is also small. At the same time one has to underline that in the polish powers system, apart from exceptional cases, networks are grounded in only one point, what allows to neglect the impact of local energy sources on zero sequence current completely.

Despite the possibility to distinguish line type affected by the fault, the proposed algorithm is capable of identifying branch affected by the earth fault. One has to underline that the possibility 
of branch identification is limited and depends on electrical parameters of power lines-mostly on cables length and earthing resistances, what is presented in the paragraph-simulation results. An additional factor affecting the proposed algorithm is connected with power system reconfiguration i.e., tie open point modification [38]. To compensate for network reconfiguration, one can send fault data and network information to the central system. Based on the data simulation model is created i.e., in PowerFactory (version 2019 SP4, DIgSILENT GmbH, Gomaringen, Germany) or PSCAD software (v6.1, Manitoba Hydro International Ltd., Winnipeg, Manitoba, Canada). Simulation software is used to obtain data for different fault locations, which are further compared with measured fault data. Simulation software can be run in background mode thanks to API interfaces [39]. It is also possible to increase the accuracy of results if weather data or other will be used to assess earthing resistance. The proposed method can be used in cable lines with different bonding configurations i.e., cross bonded lines or one point bonded lines [40].

\section{Measuring System}

The proposed solution utilizes Rogowski coils for current measurement. The measuring system is presented in Figure 3 [5]. In many places around the globe, conventional current transformers are used, however, utilization of Rogowski coils fits in world trends. One of the main reason for CT transformer installation are historical issues-current transformers not only provide measurand, but also energy to run analog relays [41]. Nowadays relays are connected to an external power supply and power from $\mathrm{CT}$ is not necessary. It is, however, difficult to replace conventional CT transformers because some protection relays are not able to read Rogowski coil signal so an old CTs are replaced with a new a one and when protection relay needs to be replaced it is adopted to an existing current sensors. Authors believe that protection relays manufacturer should equip protection relays with bigger number of inputs-Rogowski and conventional or provide accessories for signal conversion. In many cases, new protection relays already use Rogowski coil to measure secondary side transformers and some manufacturers already offer relays with both current input types [42].

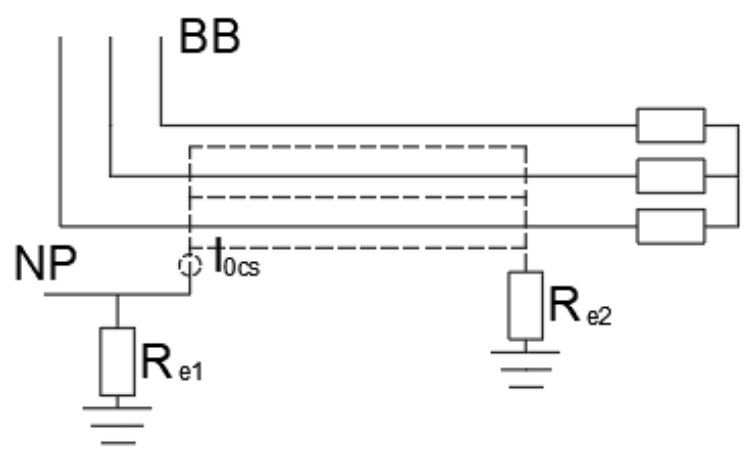

Figure 3. Measuring system; $N P$-neutral point of $\mathrm{ZNyn}$ transformer, $B B-\mathrm{MV}$ busbars, $R_{e 1}$-resistance of 110/15 earthing system; $R_{e 2}$-resistance of MV earthing system.

\section{Simulation Tests}

Earth fault current flow in the MV cable line network is presented in Figure 4. The model is built from the following components: 110/15 transformer, grounding transformer, earthing system, cable, and overhead line [43]. The cable line is modeled as a Frequency-dependent line and considers distributed parameters. 


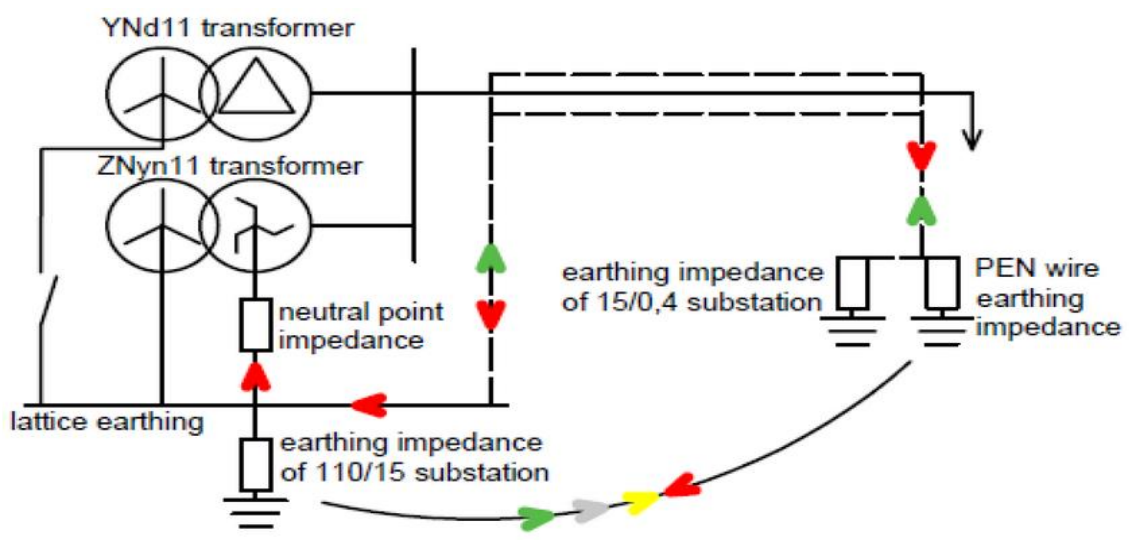

Figure 4. Cable screen current flow.

Figure 5 presents earthing current sources. The current sources marked with yellow, grey, red and green are presented in the previous author's publications [4,5]. Sources marked with red-blue and light blue are presented in the next paragraphs. Simulations were made in PSCAD software. Attention is paid on earthing resistances and the number of cable earthing points because those parameters have the biggest impact on simulation results. Moreover, earthing system resistance is a function of time i.e., resistance made of pipe $\frac{3}{4}$ inch with a length 3 feet in rocky, clay ground is varying in the range of 42 do $77 \Omega$. Depth of earthing system installation has a big impact on resistance variation i.e., 10 feet long $\frac{3}{4}$ pipe is varying in the range of 37 to $58 \Omega$ [44]. Variability of earthing resistance depends on the earthing system's spatial layout and material of the earthing system and soil type [45]. It is possible to assess earthing system resistance using weather station data or humidity sensors installed in the distribution system network.

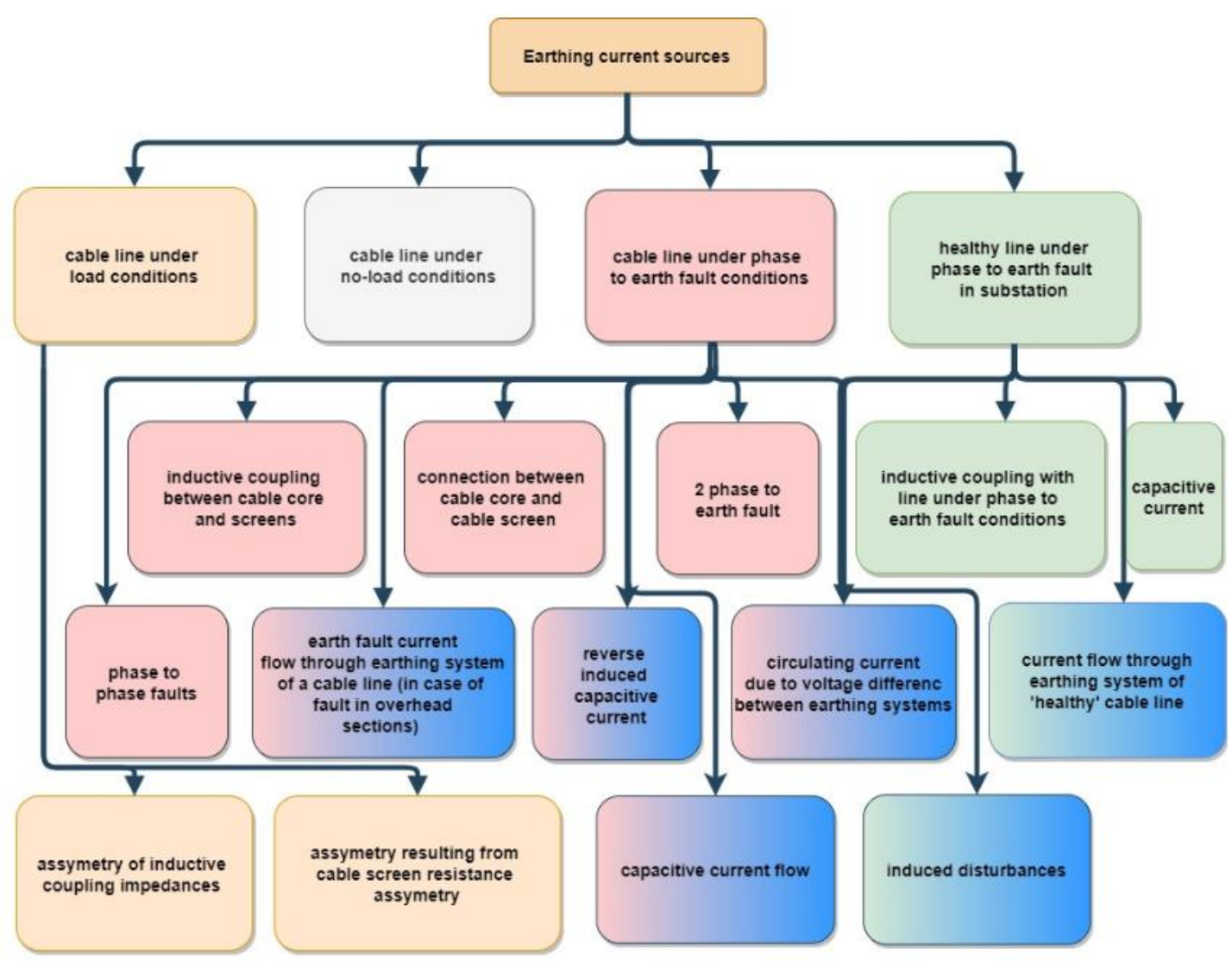

Figure 5. Earthing current sources. 
In the previous author's paper [5], a concept of faulted line identification is presented. In case of fault between cable screen and cable core, the phase shift between $I_{0 c s}$ and $I_{0 c c}$ current is 0 , whereas in case of a fault in overhead line installed after the cable the phase shift is 90 . The presented concept is a valid hover is simplified. In real cable lines, the phase shift can vary in a relatively broadband, which is presented in the paragraph.

Simulations were aimed at sensitivity analysis on a reduction factor of $110 / 15 \mathrm{kV}$ substation and phase shift between the zero-sequence current measured in cable cores and earthing current. Attention is paid on cable parameters, mostly on cable screen cross-section and cable length and earthing resistances.

Mathematical description of cable lines reduction factor is given by the formula [46]. Mathematical description of reduction factor of cables with ECC wire can be found in [47], the reduction factor of 3 core cables in [48] and in [49] reduction factor of parallel lines. Most publications focus on electrocution protection and consider a case of phase to screen fault, where touch voltage has the biggest amplitudes. A reduction factor of mixed power lines-cable, overhead lines is based on the scheme presented in Figure 6.

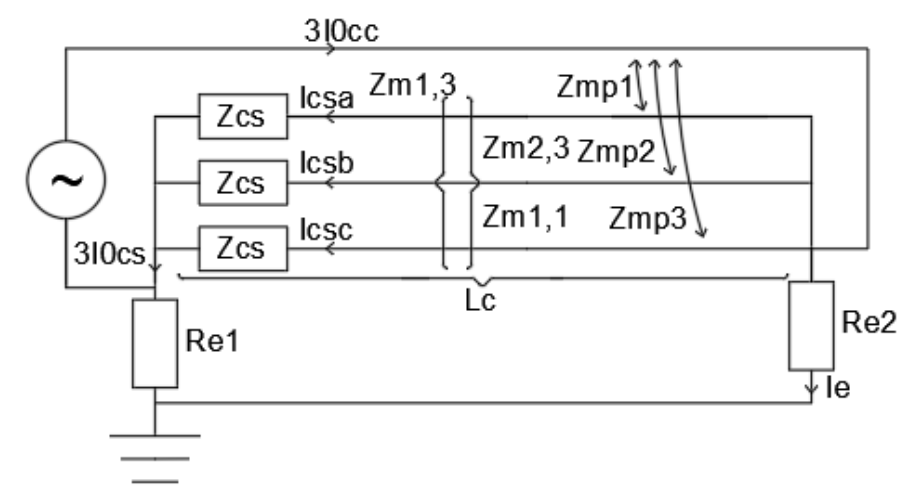

Figure 6. Coupling impedances in case of earth fault in cable, based on [50].

Relations presented in Figure 6 allows to develop following set of equations describing the cable screen earthing current:

$$
\begin{gathered}
a_{11} I_{c s a}+a_{12} I_{c s b}+a_{13} I_{c s c}=b_{1} 3 I_{0 c c} \\
a_{22} I_{c s b}+a_{21} I_{c s a}+a_{23} I_{c s c}=b_{2} 3 I_{0 c c} \\
a_{33} I_{c s c}+a_{31} I_{c s a}+a_{32} I_{c s b}=b_{3} 3 I_{0 c c} \\
I_{g r}=3 I_{0 c c}-\left(I_{c s a}+I_{c s b}+I_{c s c}\right) \\
a_{i i}=\left(R_{e 1}+L_{c} z_{c}+R_{e 2}\right) ; \quad i \in[1,3] \\
a_{i j}=\left(R_{e 1}+L_{c} z_{m i, j}+R_{e 2}\right) ; \quad i \neq j \\
b_{i}=\left(R_{e 1}+L_{c} z_{m p, i}+R_{e 2}\right) ; \quad i \in[1,3]
\end{gathered}
$$

After solving the presented set of equations using method of substitution following formulas are obtained:

$$
3 I_{0 c s}=3 I_{0 c c}\left(1-\frac{3 R_{e 1}+L_{c}\left(z_{c}-z_{m p, 1}\right)}{L_{c}\left(z_{m 1,2}+z_{z}\right)+3 R_{e 1}+3 R_{e 2}}\right)
$$

Earth fault in overhead section is also connected with electrocution hazard, it is, however, smaller than in case of fault along the cable line. Additional attention is paid on HV and EHV line because of high zero sequence currents amplitude resulting from direct earthing of neutral points. Electric shock protection requires additional analysis and is presented in [51]. 
It is also possible to identify line affected by earth fault in microgrids, what actually is simpler since lengths of lines in such grids are typically smaller. At the same time, one has to remember that microgrid requires additional protection relay-interface protection [52]. Identification and location of $2 \mathrm{fg}$ faults requires separate attention and is part of current research [53].

\subsection{Cable Lines}

Among factors, which could influence angle $\alpha$ is the self-capacitive current of the cable line. In case of uniform cable line (without additional earthing resistances) practically whole capacitive current will flow through the earthing system of $110 / 15$ substation. The capacitive current from healthy phases is then flowing to the grounded phase through MV windings of transformers. For case of simplicity only D winding of $110 / 15 \mathrm{kV}$ transformer is considered and isolated network is considered. Blue color represents the capacitive current of a cable line, whereas orange color represents capacitive current of overhead line. Idealized earth fault (fault resistance is zero) occur in place $E F_{1}$ and all capacitive current is flowing to the place of earth fault. If earth fault would occur in cable line marked with red color (location $E F_{2}$ ), the capacitive earth fault current of cable line measured at location marked with $I_{0 c s}$ would be compensated because blue arrows have opposite direction. At the same time self-capacitive current measured in cable cores would be compensated for the same reason. The current flow is presented in the Figure 7. Unfortunately, with the increase of cable length and increase of earthing system number, factors presented as negligible will play a bigger role and consequently, angle $\alpha$ will be varying. The biggest $\alpha$ and smallest $R F_{110 / 15}$ can be observed for the case of earth fault at the end of the cable line. Simulation results consider only this—worst case.

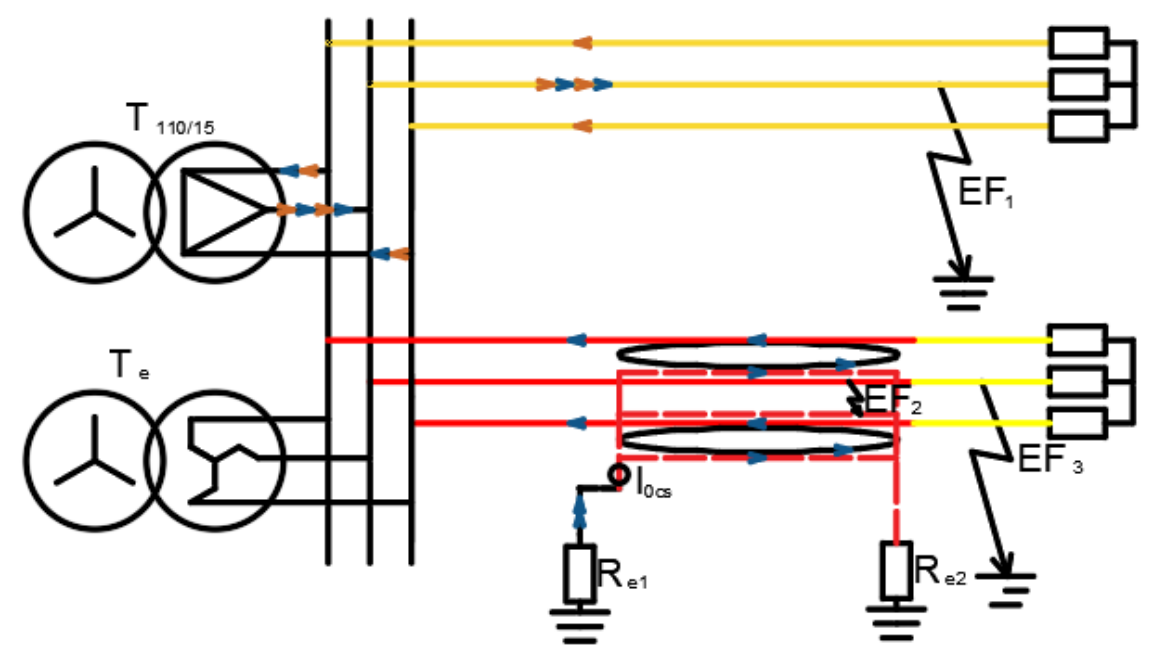

Figure 7. Capacitive component of earth fault current flow in mixed feeder; cable line marked with red; overhead line marked with yellow; another power lines marked with green; Te-grounding transformer; Ts—secondary winding of 110/15.

Another factor, which have an impact on $R F_{110 / 15}$ and angle $\alpha$ is reverse self-capacitive current, which flows to place of fault from load side and reverses induced current resulting from the flow of capacitive current as is presented in Figure 8. L1 is a length of cable between 110/15 substation and fault location, whereas L2 is the length between fault location and cable end. As can be observed self-capacitive current flows through whole cable length (L1 + L2). On the length, L1 current is compensated since current from 2 'healthy' phases is flowing to the grounded phase. On distance L2 however one can observe only current flowing to supply side, as a result zero-sequence current on distance L2 is greater than 0 and according to induction law, the current induces additional zero sequence current in cable screens. The induced zero-sequence cable screen current has a different phase shift than zero-sequence current resulting from the galvanic connection. As a result, angle $\alpha$ 
of the resulting zero sequence current is different. Despite described currents, in Figure 7, one can notice additional current marked with light blue, which is a part of self-capacitive current flowing from opposite direction. The current is usually small and negligible, however, in case of high capacitance behind the fault location i.e., long cable or MV substation the current can also influence angle $\alpha$ and $R F_{110 / 15}$. The same effect is observed in overhead line and the current is marked with yellow. Red color represents earth fault current component flowing through neutral point. The bigger the component is, the smaller is the effect of reverse capacitive current.

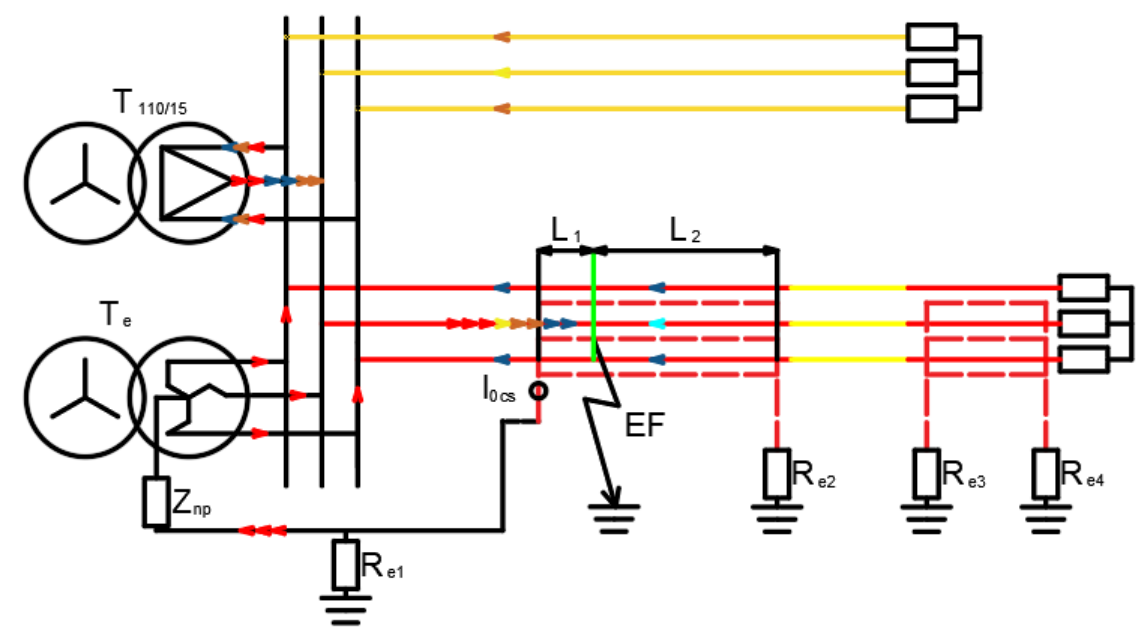

Figure 8. The idea of reverse self-current (capacitive) and reverse self-induced (capacitive) current.

Analysis of the Figures 9 and 10 allows to observe that with the increase of cable length, angle $\alpha$ is rising. When cable length increases, an amplitude of earth fault current returning to the 110/15 station is reduced at the same time a difference between $I_{0 c s}$ and $I_{0 c c}$ is rising-what results in a rise of a magnetic field, which induces a current in cable screens. Current flowing through cable screens is a combination of current resulting from galvanic connection and induction. With the rise of cable length, an amplitude of MV earthing system current rises and at the same time voltage resulting from current flow through earthing resistance increases. As a consequence, voltage difference between earthing system at load side and supply side increases, what in turn can induce a flow of circulating current.

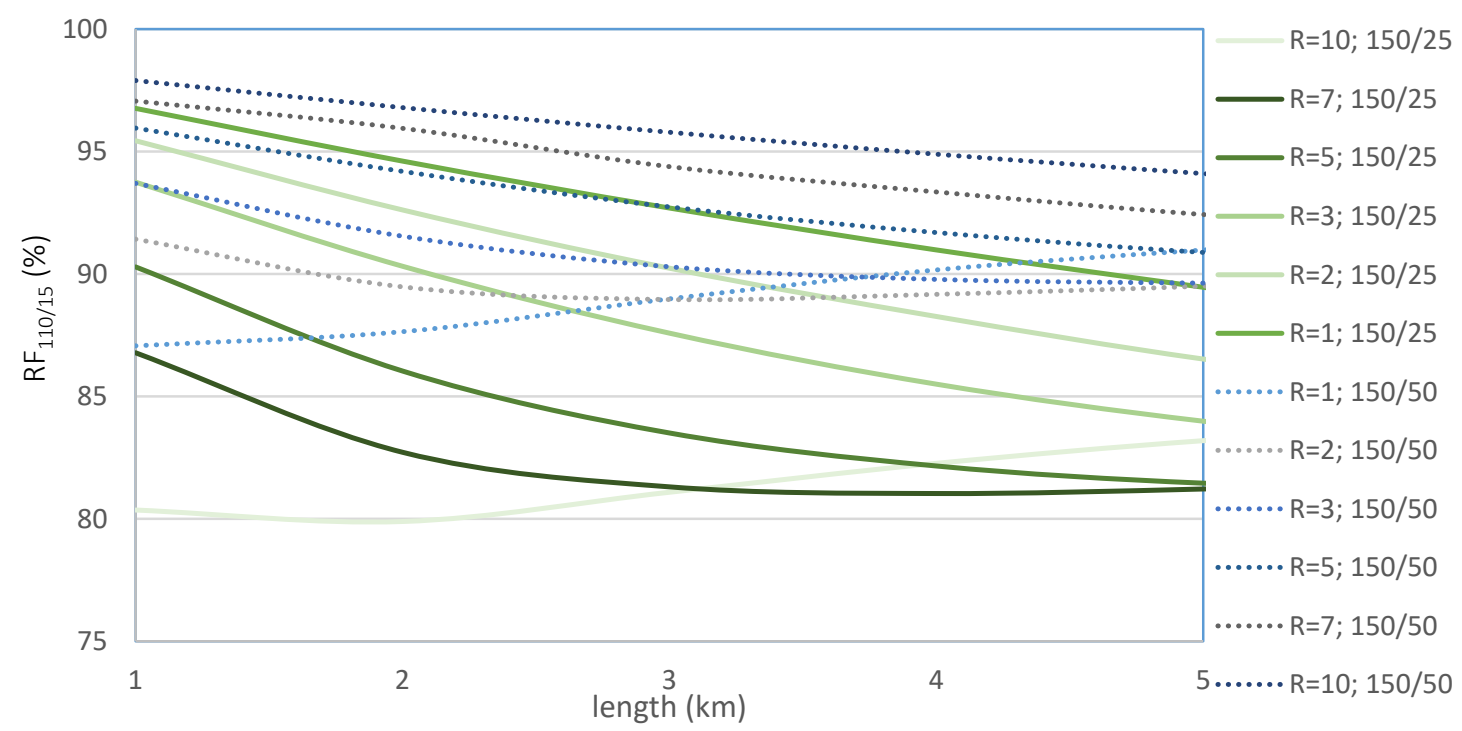

Figure 9. $R F_{110 / 15}$ for faults between cable core and screen at the end of the cable line in a trefoil configuration. 


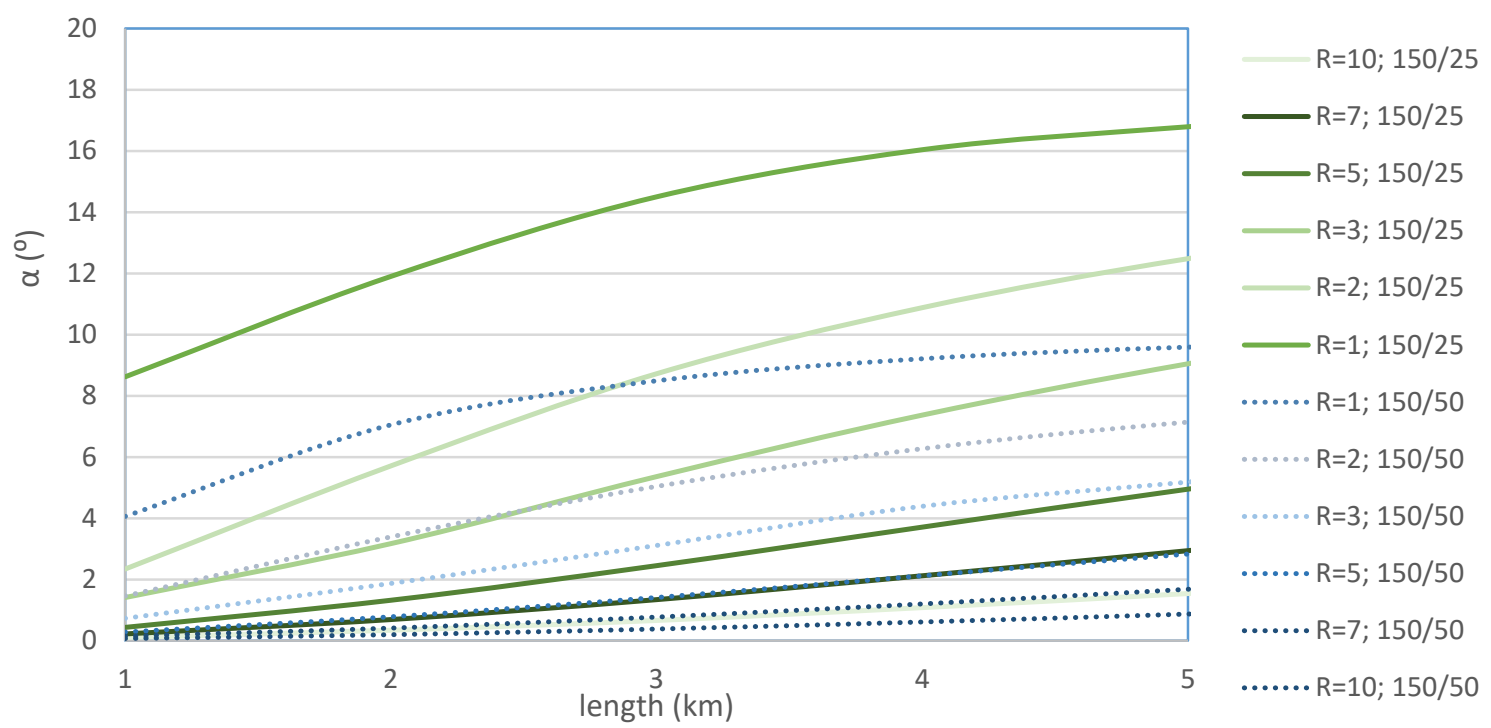

Figure 10. $\alpha$ for faults between cable core and screen at the end of cable line in a trefoil configuration.

\subsection{Cable-Overhead Lines}

In case of earth fault in overhead section of mixed feeder in the ideal case-short cable line grounded with high resistance, angle $\alpha$ is $90^{\circ}$. With an increase in the length of cable, more and more current is flowing through the earthing system instead of screens of 'healthy' phases. Earthing system of MV network has resistive character and therefore angle $\alpha$ is changed.

The number of earthing systems and resistance has a big impact on earth fault current flow. In order to assess the impact of the parameters on $\alpha$ and $R F_{110 / 15}$, a model presented in Figure 11 is developed. It is assumed that the same cable type is used $3 \times 150 / 25$ or $3 \times 150 / 50$, which is clearly a simplification since normally cross-section of cable core and screen is reduced since fault current is reduced by increasing length of lines (lines impedance), what naturally limits short circuit power and thermal stress.

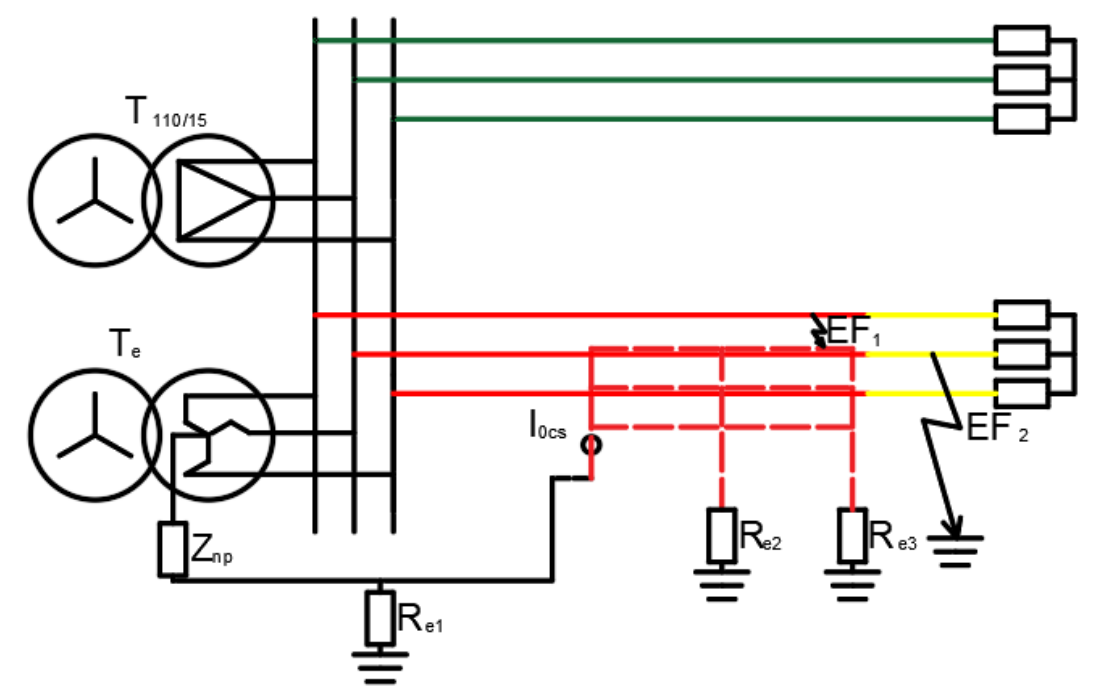

Figure 11. A model for testing the impact of the number and earthing systems of a cable line on the earth fault current distribution.

Simulation results for faults outside the cable line are presented in Figures 12 and 13. It is assumed that resistance of the earthing system is below $10 \Omega-1,2,3,5,7$ or $10 \Omega$ and earth resistivity is 
$200 \Omega \mathrm{m}$ [54]. Surface earth resistivity has an impact on current induced in the earth around the cable line [55].

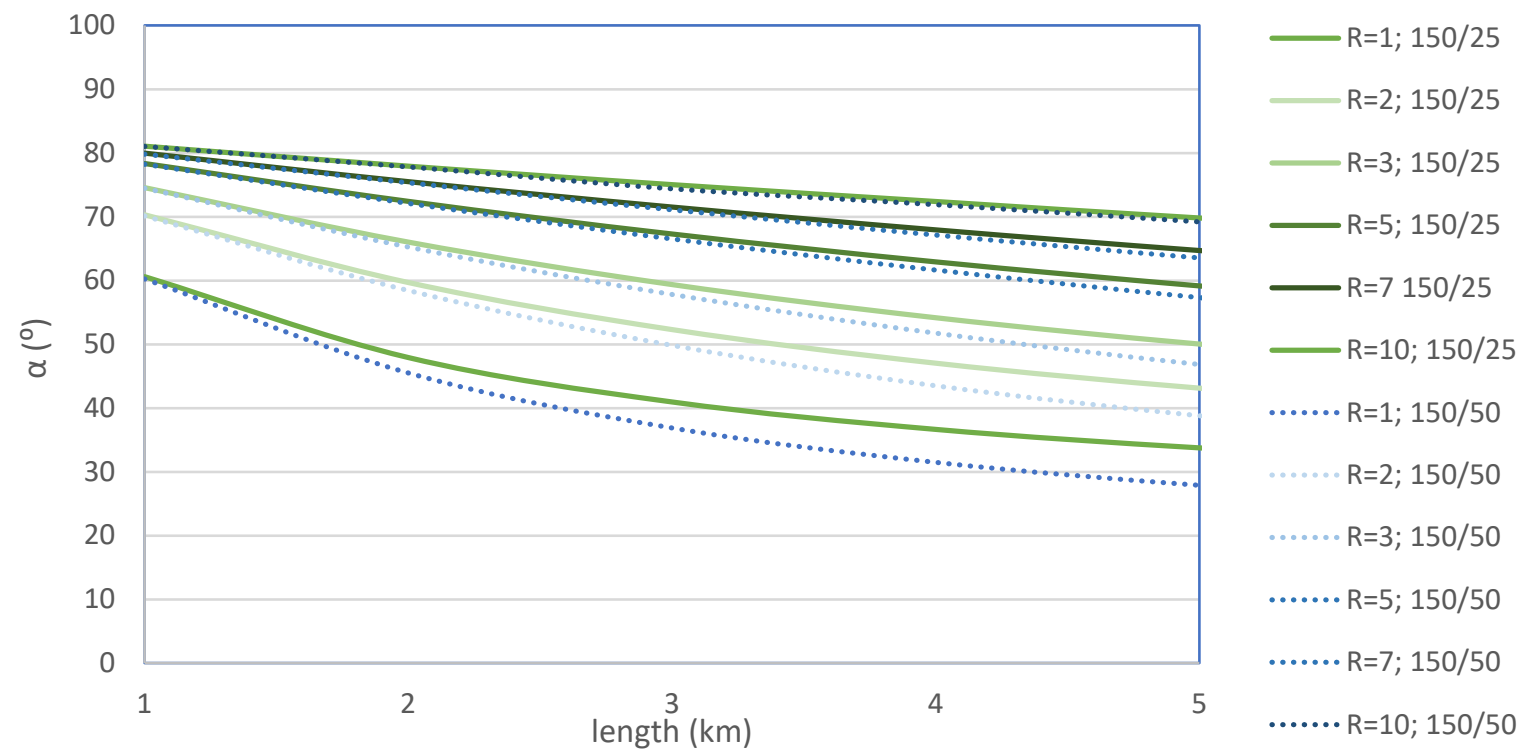

Figure 12. $\alpha$ for faults in overhead section of mixed feeder (cable in a trefoil configuration).
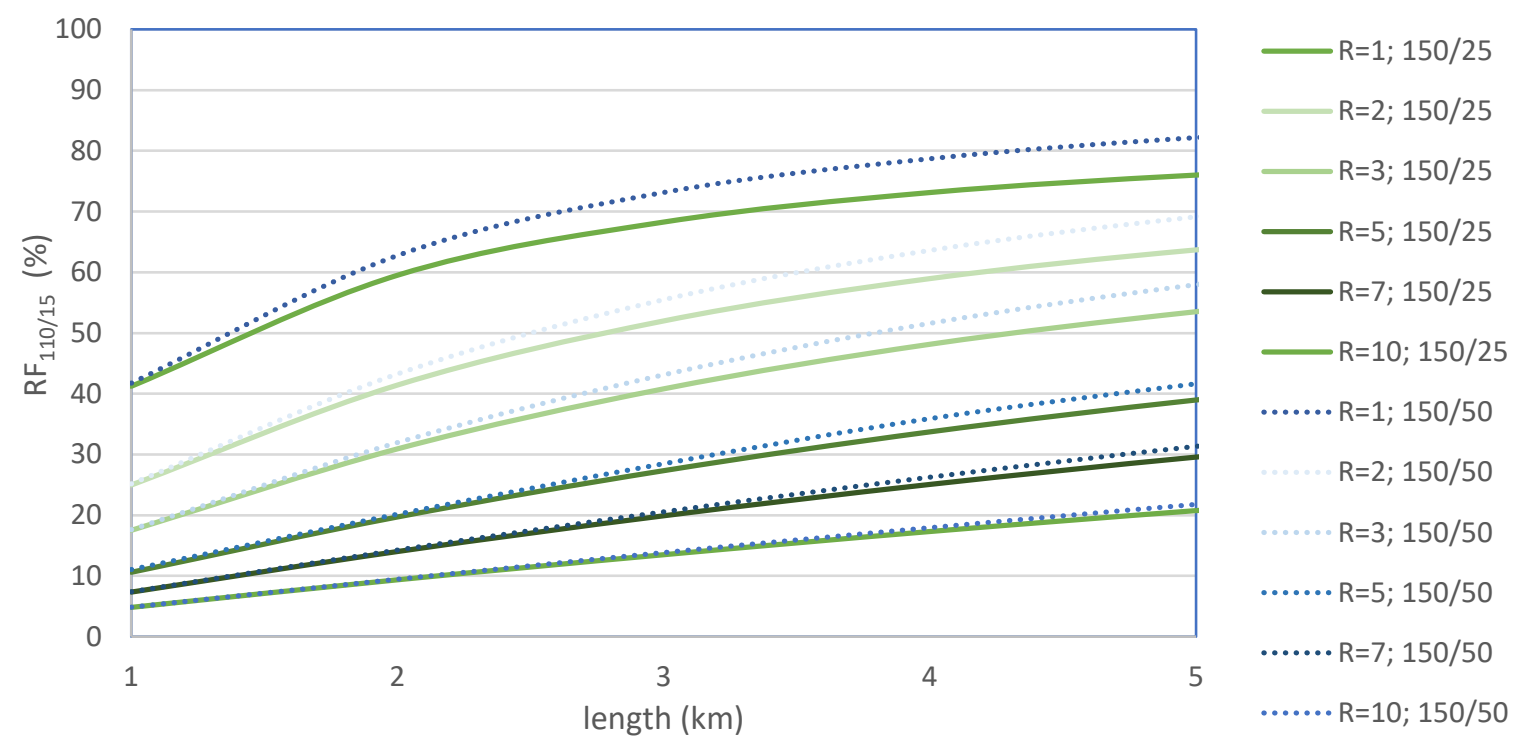

Figure 13. $R F_{110 / 15}$ for faults in overhead section of mixed feeder (cable in a trefoil configuration).

As is presented in Figures 12 and 13, cable screen cross section has limited impact on results. Increase of cable length leads to an increase of the $R F_{110 / 15}$ and decrease of the $\alpha$. Increase of $R$ earth leads to decrease of the $R F_{110 / 15}$ and increase of the $\alpha$. Presented relations make identification of line type more difficult-the precise measurement of $I_{0 c c}$ and $I_{0 c s}$ currents is required. At some point, it is practically impossible. The maximum cable length, which allows for proper identification in case of cable lines with just one earthing system at the end is approximately $10 \mathrm{~km}$. One has to however underline that when the length of the cable increases the uncertainty of simulation results also increase therefore results are limited to $5 \mathrm{~km}$ long cable to avoid hasty conclusions.

A big number of factors affecting $R F_{110 / 15}$ and angle $\alpha$ make the analysis more difficult, however, the presented result confirms that the presented concept can be used in real-life scenarios to distinguish between faults in cable and overhead sections. 
There is boundary earth fault condition-fault in a transition point-change of line type. In this case, $R F_{110 / 15}$ and $\alpha$ can be strongly affected if earthing resistance is comparable with surface earth resistivity and resulting resistance between cable screens and fault location.

Figures 14 and 15 present impact of earthing system number on $R F_{110 / 15}$ and $\alpha$. Increasing cable length and number of earthing systems makes the identification of line type affected by the fault more and more difficult and at some point, it becomes impossible. 3 core cable, which is almost completely replaced with 1 core cable in most countries could have a different type of cable sheath, but in most cases, the sheath was made of uninsulated $\mathrm{Pb}$ alloy. The sheath acts as a multi-point (indefinitely large) grounding system and therefore presented criteria are not operational in these types of lines i.e., AKnFt [56]. It is possible to use the presented criteria in 3 core cables with XLPE insulation, which are installed in Scotch MV networks [57].

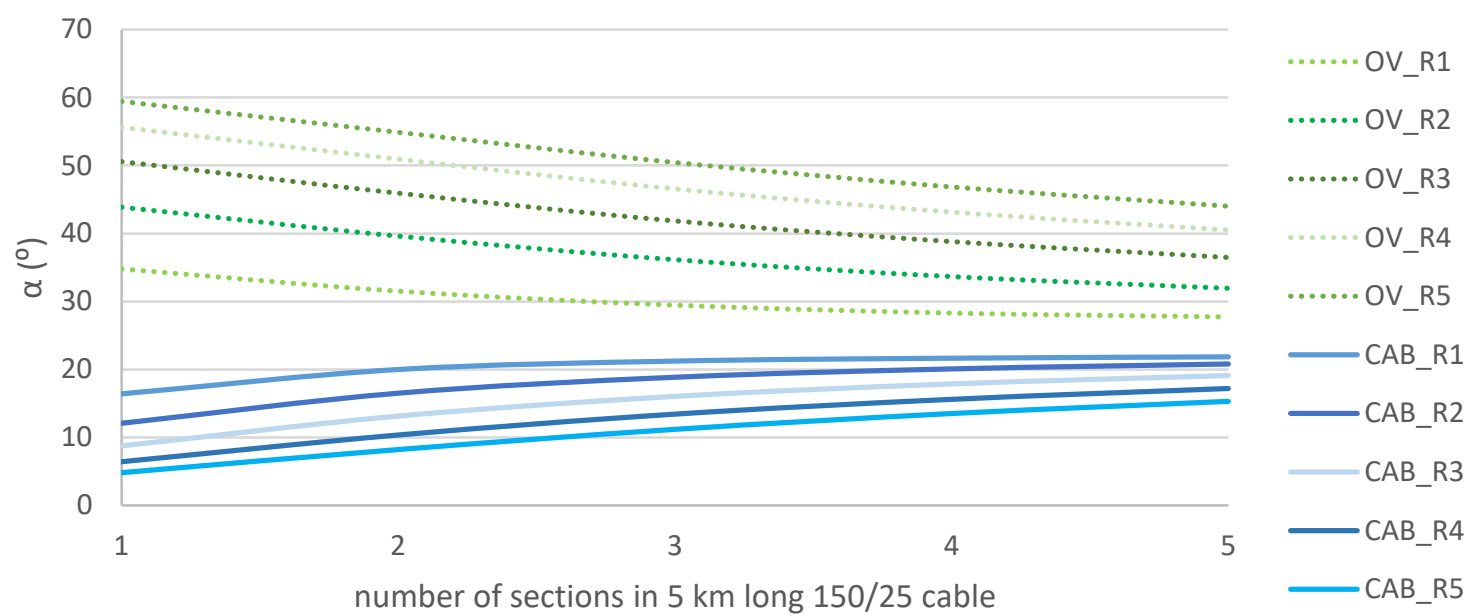

Figure 14. Impact of earthing system number on angle $\alpha$.

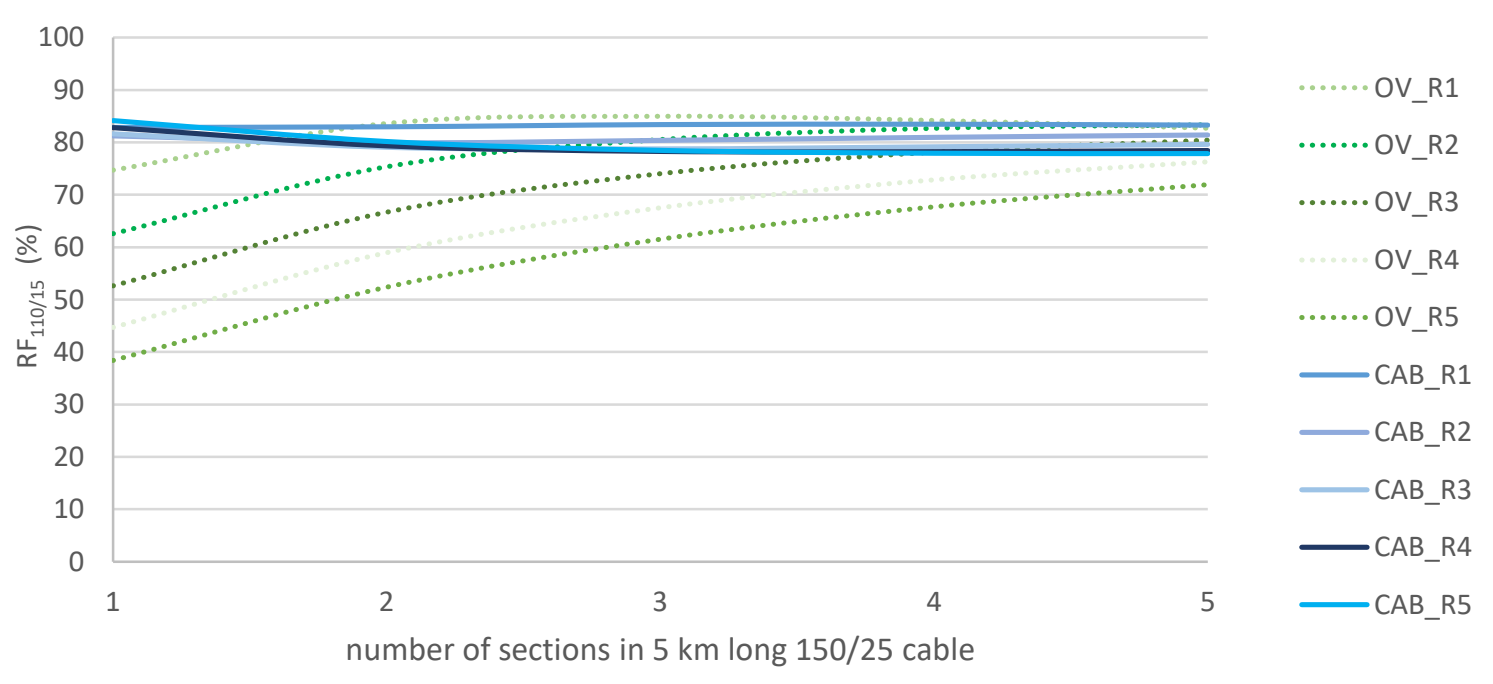

Figure 15. Impact of earthing system number on $R F_{110 / 15}$.

Further analysis allows to conclude that the presented method could be adjusted to complex-multi-branch feeders (Figure 16), which are quite common in distribution system network and are included in benchmark models i.e., CIGRE [58]. The idea is based on previously presented relations-change of induced current in the function of line length. If branches are created by cables, which lengths differ significantly or resistances of earthing systems in different branches differ significantly one can observe the significant change of induced currents. As a result, one can reduce time to locate failure since a significant part of the feeder can be excluded from the search 
area. The proposed methodology is very interesting, but unfortunately not universal. In some feeders, the proposed method could be a very effective tool for earth fault location and identification, whereas in different feeders it is only possible to identify the type of line affected by the fault. It is believed that distribution feeders should be analyzed in the context of the effectiveness of the proposed method. If the method is effective one can resign from the installation of fault current indicators, which are effective, but cumbersome solution.

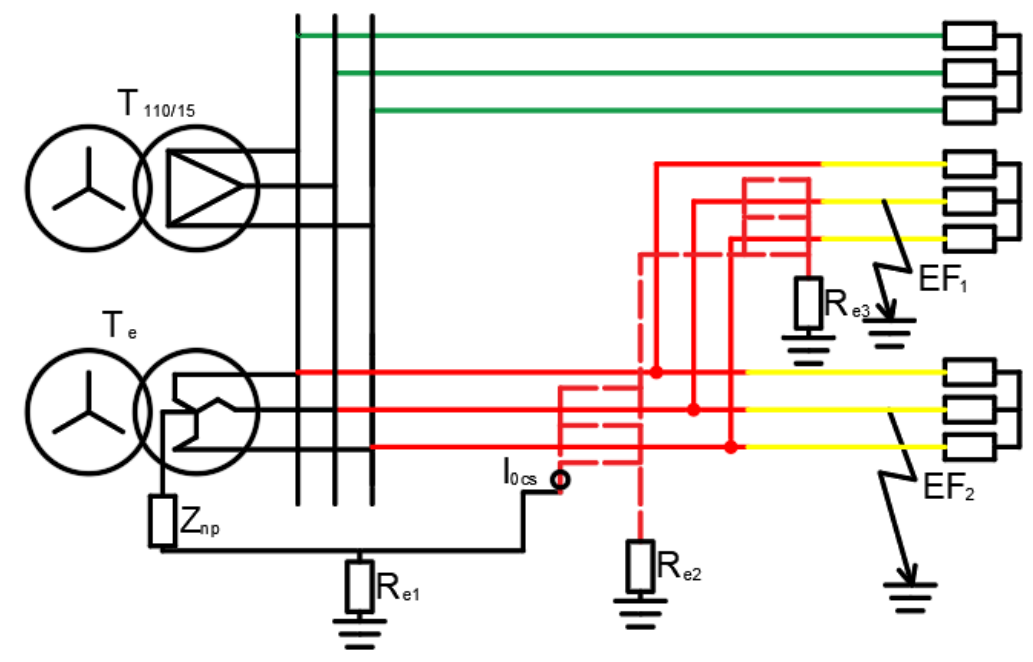

Figure 16. Analysis of branches affected by ground faults.

\section{Research in the MV Network}

Measurements in MV networks are taken at a new mixed feeder. Cable line connected with 110/15 station is made of $3 \times N A 2 X S(F) 2 . Y 150 / 2512 / 20 \mathrm{kV}$ cable, which is $370 \mathrm{~m}$ long. The measurement system is presented in Figure 17. Rogowski coils are installed on cable cores and screens and additional fault recorder is installed at the secondary side of instrument transformers. The role of the additional recorder is to verify measuring errors at the secondary side. In this particular case, brand new current transformers with low ratio 75:5 allowed to get the acceptable measuring error-amplitude error below $5 \%$ and phase error in range $10-15^{\circ}$.

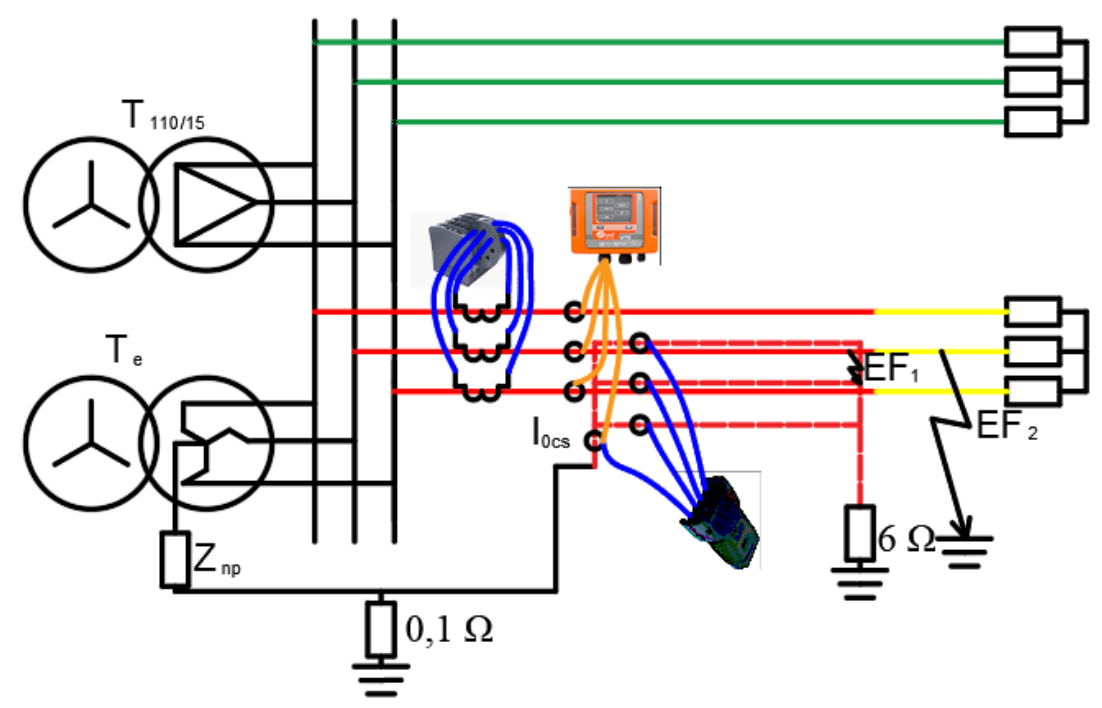

Figure 17. Diagram of the measuring system. 
The tests were based on applying an artificial connection between the working conductor and the cable screens with the help of a controlled circuit breaker. During the tests, the number of cable screens connected to the earth earthing system was changed and no effect on the natural current flowing in healthy phases was noticed. Overvoltages in grounded return screens were also measured during the tests to determine the risk to cable screens, but the subject is analyzed in separate project.

Table 2 presents the results of the network tests. After test number $2 b$ one of the lines was switched and as a result earth fault current is changed significantly since tests were carried out in compensated network with tap regulated coil in neutral point. As can be observed simulation results and measurement results were similar with an error below $5 \%$. Figure 18 presents cable screen and core waveforms for case number 1, after operation of the active current forcing system, presented in Table 2, as can be observed currents flow evenly in all phases, but one can observe additional distortions in cable, through which an earthing current is flowing.

Table 2. Results of network tests.

\begin{tabular}{|c|c|c|c|c|c|c|c|c|c|c|c|c|}
\hline Lp. & \multicolumn{4}{|c|}{ Measurements in MV } & \multicolumn{3}{|c|}{ Connection with Ground } & \multicolumn{3}{|c|}{ Simulation Results } & \multicolumn{2}{|c|}{ Simulation Errors } \\
\hline 1 & 44.025 & 42.706 & 1.75 & 97.0 & 1 & 1 & 1 & 43.384 & 0.03 & 98.5 & 1.59 & -1.91 \\
\hline $2 b$ & 42.67 & 40.208 & 2.7 & 94.2 & 1 & 0 & 1 & 41.759 & 0.14 & 97.9 & 3.89 & -2.84 \\
\hline $3 a$ & 34.865 & 33.347 & 1.98 & 95.6 & 0 & 0 & 1 & 33.401 & 0.29 & 95.8 & 0.21 & -1.88 \\
\hline $3 b$ & 33.391 & 31.278 & 1.44 & 93.7 & 0 & 0 & 1 & 31.992 & 0.29 & 95.8 & 2.25 & -1.28 \\
\hline $4 b$ & 31.814 & 29.631 & 2.79 & 93.1 & 0 & 1 & 1 & 31.168 & 0.04 & 98.0 & 5.23 & -3.06 \\
\hline 5 & 31.601 & 0.677 & 86.9 & 2.14 & 1 & 1 & 1 & 0.891 & 81.84 & 2.8 & 31.75 & -5.62 \\
\hline
\end{tabular}

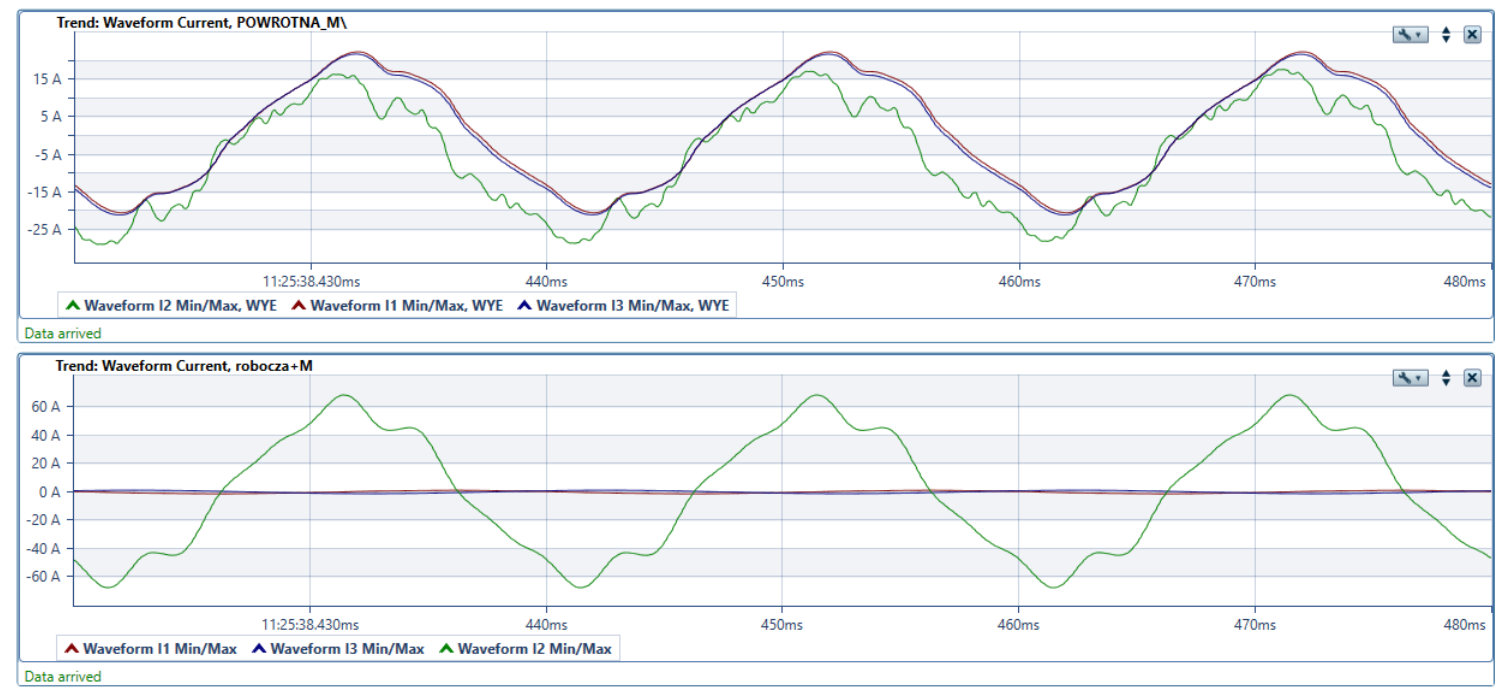

Figure 18. Fault between cable screen and core (nr 1 in Table 2) of 2 points bonded cable.

High harmonics content could have a negative influence on the operation of protection relays and therefore the signal is typically filtered to remove unwanted components of the signal-in case of the proposed solution only fundamental component is left [59].

\section{Developed Algorithms}

Presented results can be expressed as the $R F_{110 / 15}$ in a function of $\alpha$, which allows for simpler identification of line type affected by the fault. Figure 19 presents results presented in Figures 9, 10, 12 and 13 expressed in $R F_{110 / 15} / \alpha$ plane for different grounding resistances 1, 2, 3, 5, 7 and 
$10 \Omega$ and length of cable lines in range of 1 to $5 \mathrm{~km}$. Shades of gray represent faults at the end of the cable line and shades of blue represent faults in overhead lines. Dashed lines determine 2 zones-fault in cable line is marked in section defined by dotted black lines and earth faults in overhead section of the protected feeder are marked with blue, dotted lines. As can be seen zones are slightly shifted from simulation results, what is needed to cope with simulation errors and modeling inaccuracies. Precise value of correction factors is not known - typically in case of protection relays correction factors are set based on operational experience [60].
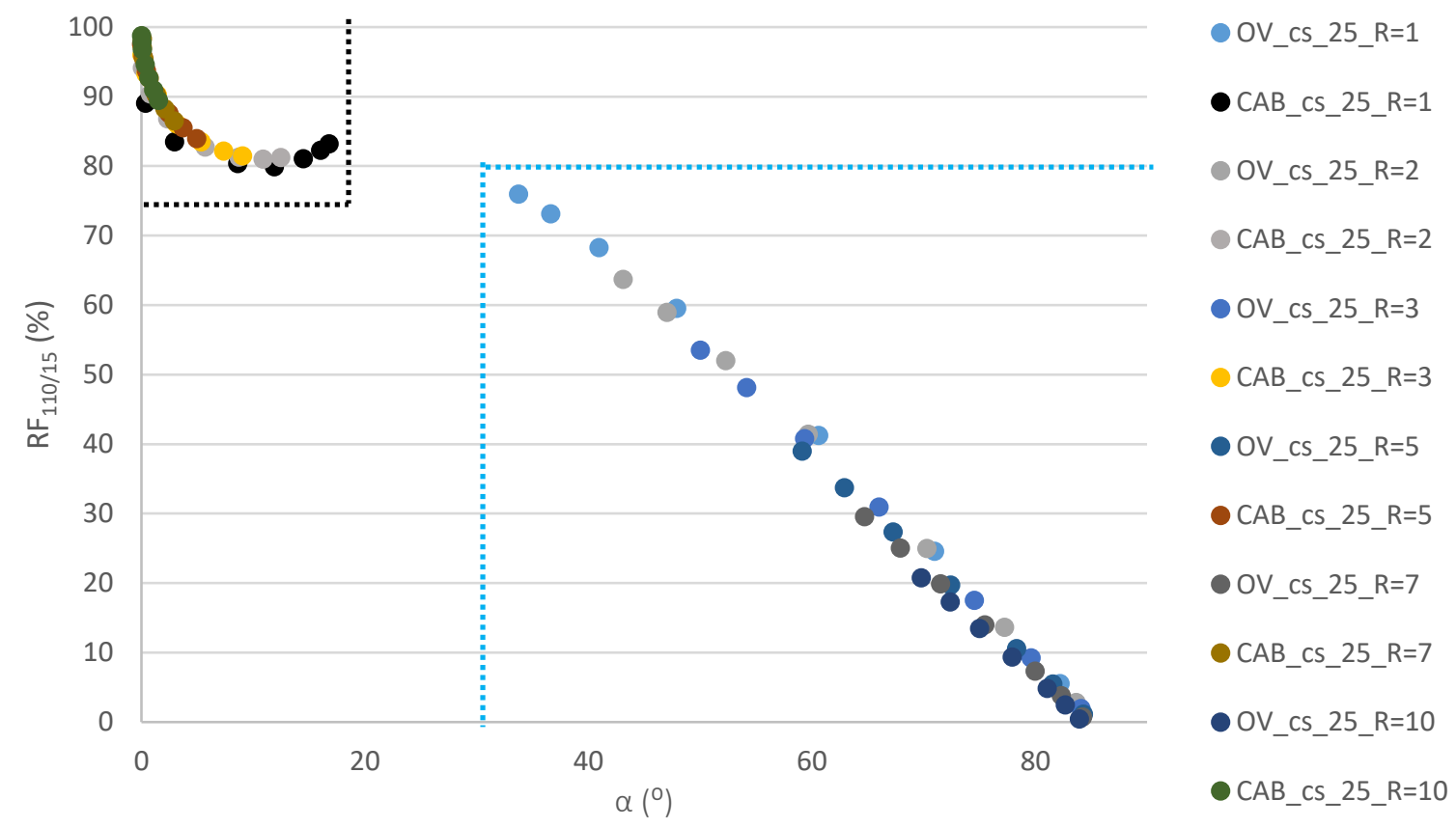

Figure 19. $R F_{110 / 15} / \alpha$ characteristic.

Presented considerations allowed for the development of an algorithm for earth fault location and identification of the faulted line. The big advantage od line recognition is the possibility to block auto-reclose devices in case of failures along the cable, which are permanent. Moreover, 2 time settings - fast for earth faults along the cable line and slow for fault in overhead line sections can be used to ensure compromise between the reliability of supply and insulation stresses. The algorithm presented in Figure 20 analyzes angle $\alpha$ and $R F_{110 / 15}$ and use conventional comparators to determine if measurands are inside the protection zones. If measured values are within area 1 a fault in the cable is recognized, in the range 2-fault in overhead section. Analysis of Figures 8, 9, 13 and 14 allows to notice that in case of short cable lines $-<3 \mathrm{~km}$, it is possible to analyze only $\mathrm{RF}_{110 / 15}$ in order to determine if fault occurred in a cable line or outside - in overhead section. One can conclude practical conclusion-in case of short cable lines it is not necessary to replace conventional CT with Rogowski coil in order to use the presented criterion. As is presented in previous author's paper, in case of low current flowing through primary side conventional CT can introduce big measuring error - even $20 \%$. In order to avoid negative impact, i.e., unwanted tripping, of the error on protection algorithm CT loading block is introduced (I_load > Imin_load). If loading of primary side CT is below threshold, algorithm makes the decision about tripping based solely on $Y_{0 c s}$, which is modified admittance protection criterion, obtained according to formula:

$$
Y_{0 c s}=\frac{I_{0 c s}}{U_{0}}
$$

where $U_{0}$ is zero sequence voltage. 


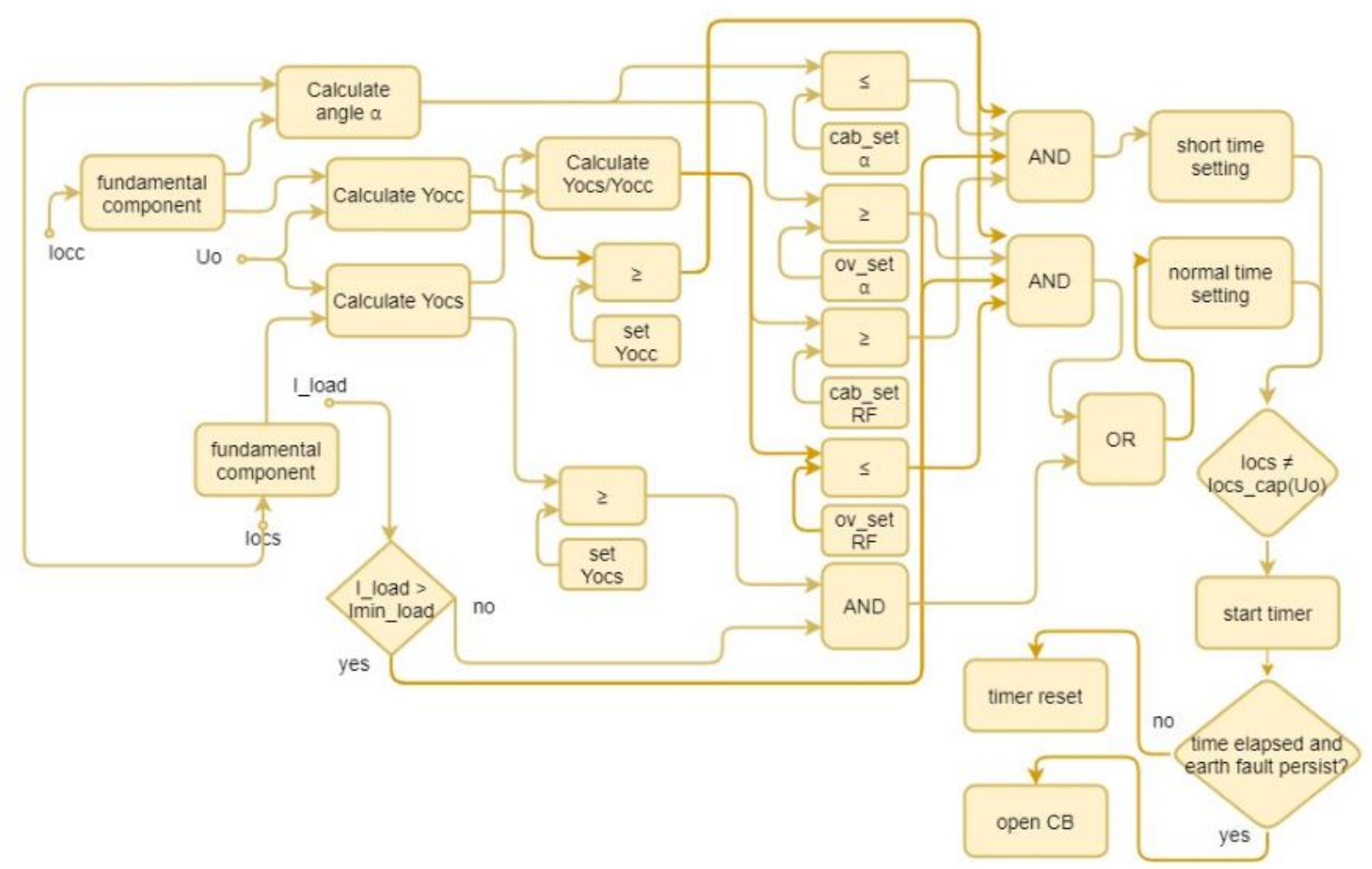

Figure 20. An algorithm for fault detection and identification of line type affected by earth fault.

Preliminary research confirmed that similar characteristics are obtained for cable lines in depths of the network-not connected with $110 / 15 \mathrm{kV}$ station. Topic is currently analyzed and is a part of future research.

After protected feeder is de energized, the fault location general algorithm presented in Figure 21 is started. The general procedure is based on utilization of simulation software or mathematical model. Detailed description of cable line model can be found in PhD thesis [61]. Due to the model complexity, the algorithm requires relatively big amount of time to identify branch affected by earth fault or determine distance to earth fault. As a result, it is not possible, assuming reasonable cost of protection relay, to use the algorithm in real time.

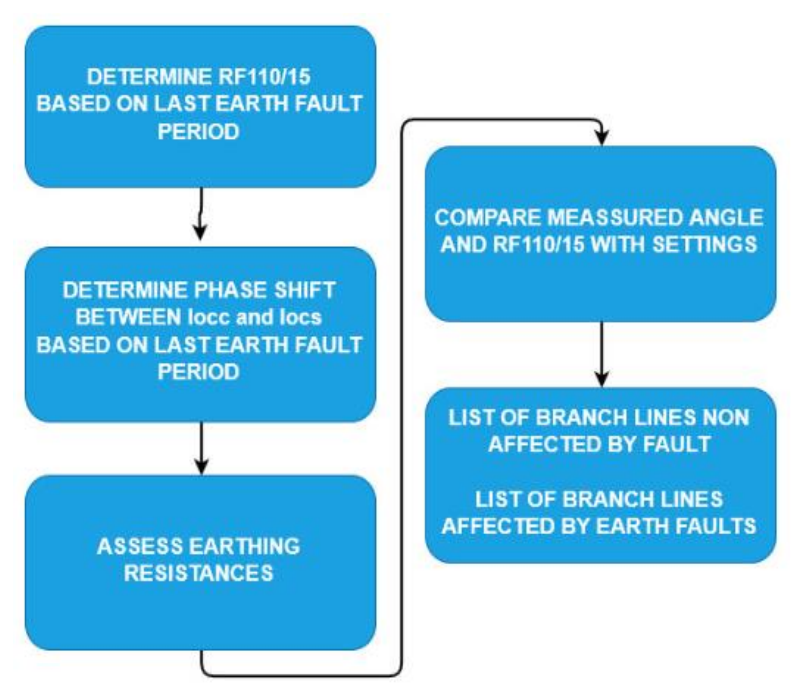

Figure 21. General fault location algorithm. 
The fault location procedure is started after measured signals: $U_{0}, I_{0 c c}, I_{0 c s}$ and information about present system configuration are send to the system. After obtaining information about the system configuration the simulation model is updated. Moreover, it is possible to adjust earthing resistances if weather, particularly rain information is provided. Afterwards faults in key locations are simulated-in case of an earth fault in one of overhead sections fault at the beginning of overhead lines are simulated, whereas if an earth fault is identified in cable sections-fault is simulated in the places of cable line branching. Simulation results are compared with measurement results. Differences between simulation results and measured values are calculated. The fault location characterized via the smallest difference is chosen as faulted branch. After faulted cable branch is identified, simulations are resumed, however this time, simulated fault locations are changed and the fault is simulated along faulted cable branch. Simulation results are again compared with measurement results and place characterized by the smallest difference is indicated as fault location. In some cases, similar electric parameters of branches, it is not possible to identify just 1 fault location since simulation results could be very similar i.e., just $5 \%$ difference between results. In case of small differences between simulation results, a list of results is send to grid operator. Finally, operator obtain simulation results-if one branch is affected information to repair team is send immediately, however in case of more potential fault locations are indicated, the grid operator need to coordinate repair action. It is also possible to use statistical data or operator experience to choose branch, which is more likely to be short-circuited. Both, simulation and measurement results are saved in the system database in order to observe effectiveness of the proposed solution.

In order to understand performance of the developed algorithm, a performance comparison is given in Table 3.

Comparison of different earth fault location solutions clearly shows that in case of single point grounded cable lines, developed solution is preferred solution. Furthermore, developed solution has big performance in case of short lines since installation of additional fault current indicators is not justified from economical point of view. Furthermore, the proposed solution is the preferred choice in case of lines with branches. At the same time one has to notice that the proposed solution operates properly if length of cable lines creating different branches differ significantly-at least $1 \mathrm{~km}$ for the same grounding resistance or grounding resistance differ significantly i.e., 2 and $5 \mathrm{ohms}$. Therefore, if the proposed solution is not working one can use fault current indicators. As is presented in table distance relay performance for earth fault location is small, but one has to notice that distance protection can locate phase to phase faults with relatively high precision. Fault current indicators are preferred solutions for overhead lines. 
Table 3. Performance of the RF/ $\alpha$, fault current indicators and distance relay for earth faults in MV networks.

\begin{tabular}{|c|c|c|c|c|}
\hline Case 1 (Figure 1, 5, $10 \mathrm{~km}$ ) & Location of Earth Fault in Cable Line & Location of Earth Fault in Overhead Line & $\begin{array}{l}\text { Identification of Line Type Affected } \\
\text { by Fault and Auto-Reclose Blocking } \\
\text { for Earth Faults in Cable Line }\end{array}$ & Identification of Branch \\
\hline \multicolumn{5}{|c|}{ Case 1 (Figure 6) cable $1 \mathrm{~km}$ overhead section $1 \mathrm{~km}$} \\
\hline Distance & No & No & no & na \\
\hline Fault indicator & $\mathrm{No}^{1}$ & Yes, but because of operation issues is not installed & Yes $^{2}$ & na \\
\hline Developed criteria & Yes & No & Yes & na \\
\hline \multicolumn{5}{|c|}{ Case 1 (Figure 6) cable $5 \mathrm{~km}$ overhead section $5 \mathrm{~km}$} \\
\hline Distance & No & No & limited & na \\
\hline Fault indicator & $\mathrm{No}^{1}$ & yes & Yes $^{2}$ & na \\
\hline Developed criteria & Yes & No & Yes & na \\
\hline \multicolumn{5}{|c|}{ Case 2 (Figure 7) cable $1 \mathrm{~km}$ overhead section $1 \mathrm{~km}$ and $10 \mathrm{~km}$ cable line } \\
\hline Distance & No & No & No & na \\
\hline Fault indicator & No & Yes, but because of operation issues is not installed & yes & na \\
\hline Developed criteria & Require special attention in compensated networks & No & Yes & na \\
\hline \multicolumn{5}{|c|}{ Case 2 (Figure 7) cable $5 \mathrm{~km}$ overhead section $5 \mathrm{~km}$ and $10 \mathrm{~km}$ cable line } \\
\hline Distance & No & No & No & na \\
\hline Fault indicator & No & Yes, but because of operation issues is not installed & yes & na \\
\hline Developed criteria & Require special attention in compensated networks & No & Yes & na \\
\hline \multicolumn{5}{|c|}{ Case 2 (Figure 10) cable $1 \mathrm{~km}$ overhead section $1 \mathrm{~km}$} \\
\hline Distance & No & No & No & na \\
\hline Fault indicator & Segment between $R_{e 1}$ and $R_{e 2}$ or segment between $R_{e 2}$ and $R_{e 3} \mathrm{~d}$ & Yes, but because of operation issues is not installed & yes & na \\
\hline Developed criteria & yes & No & Yes & na \\
\hline \multicolumn{5}{|c|}{ Case 2 (Figure 10) cable $1 \mathrm{~km}$ overhead section $10 \mathrm{~km}$} \\
\hline Distance & No & No & No & na \\
\hline Fault indicator & Segment between $R_{e 1}$ and $R_{e 2}$ or segment between $R_{e 2}$ and $R_{e 3}$ & Yes, but because of operation issues is not installed & yes & na \\
\hline Developed criteria & $\begin{array}{l}\text { Performance depend on number of earthing points and earthing } \\
\text { resistance. }\end{array}$ & No & Yes & na \\
\hline \multicolumn{5}{|c|}{ Case 2 (Figure 15) cable $1 \mathrm{~km}$ and $3 \mathrm{~km}$, overhead section $10 \mathrm{~km}$} \\
\hline Distance & No & No & No & No \\
\hline Fault indicator & Segment between $R_{e 1}$ and $R_{e 2}$ or segment between $R_{e 2}$ and $R_{e 3}$ & Yes & yes & Yes, if earth fault indicator is installed \\
\hline Developed criteria & $\begin{array}{l}\text { Performance depend on number of earthing points and earthing } \\
\text { resistance.-If points on } R F_{110 / 15}=\mathrm{f}(\alpha) \text { differ significantly } \\
\text { (Figure 18). }\end{array}$ & No & Yes & Yes, for faults in overhead lines \\
\hline
\end{tabular}

1. Can be installed only in places where cable screen is removed. ${ }^{2 .}$ Earth fault current indicator installed at transition point $\left(R e_{2}\right)$. 


\section{Summary}

At the beginning of the paper, review of materials about earth fault location in distribution system network is presented. Furthermore, comparison of chosen earth fault location methods-fault current indicators, distance protection and proposed solution is made. New criterion values are presented-phase shift between zero sequence current and cable screen earthing current and ratio of cable screen earthing current and zero sequence current-return factor $\left(R F_{110 / 15}\right)$. Different earthing screen current sources are presented and analyzed in order to ensure proper, sensitive operation of earth fault protection and at the same time eliminate a risk of unwanted tripping of earth fault protection. Simplified mathematical model describing earth fault current flow in cable lines is presented, what allows to understand the principle of operation. Further, different feeder configurations and factors affecting performance of the developed solutions are presented. Graphs showing criterion quantities are described. After simulation result, the developed algorithms for earth fault identification and location are presented. Additionally, SWOT analysis results and performance analysis of the proposed solution and conventional fault location methods is presented below.

Strengths:

1. no communication required;

2. cost effective single point measuring;

3. the developed algorithm can detect earth faults in case of zero sequence voltage or current transformer failure;

4. operate properly in case of neutral point impedance/transformer failure.

Weakness:

1. simplified analytical expression is not sufficient for different cases and therefore it is recommended to use simulation software for analysis of real cable line. Proposed approach may be problematic in some countries;

2. proposed solution is not universal and, in some cases, (presented in Table 3), the effectiveness could be reduced.

Opportunities:

1. further features can be integrated i.e., monitoring of cable screen connections or monitoring of stray currents;

2. improvement of reliability of supply in place where conventional technologies are not justified from economical point of view i.e., suburban areas.

Threats:

1. training for utility employees is needed;

2. it is not always clear what is the lowest value of earthing resistance of complex earthing system and therefore further research activities may be needed.

\section{Conclusions}

The contribution of the paper is connected with identification of new value, which is used as a criterion for earth fault detection and location. The proposed value-phase shift between zero sequence current and cable screen earthing current is combined with previously presented ratio of cable screen earthing current and zero sequence current. It is proposed to present values on $x-y$ plane, where the angle is on $\mathrm{x}$ axis and the ratio, referred as return factor $\left(R F_{110 / 15}\right)$ is on $\mathrm{y}$ axis. Proposed representation of criterion values greatly simplifies analysis. The proposed criterion is based on single point measurement and allows for clear identification of line type affected by earth fault. Proposed solution has unique feature, which allow to identify branch of line affected by an earth fault. Principle of operation of the proposed solutions is presented and the different screen earthing 
current sources are analyzed in order to ensure sensitive earth fault protection and eliminate a risk of unwanted tripping of earth fault protection.

Presented solutions can be applied in distribution system networks and reduce downtime after earth faults. Downtime reduction is really important for power system reliability, which among power distribution loss reduction are 2 main driving forces of power system research [62].

In some cases, just $R F_{110 / 15}$ is enough to identify the type of line affected by an earth fault, but in case of longer cable lines $\left(\geq 2.5 \mathrm{~km}\right.$ ), one has to measure angle $\alpha$ between $I_{0 c c}$ and $I_{0 c s}$. Results of conducted network tests and experience indicate that residual connection current transformer is often characterized by big measuring errors (angle) and therefore it is recommended to use Rogowski coils for measurements.

The proposed solution is characterized by very good operational performance and practically $100 \%$ effectiveness in case of an earth faults of many MV lines. It is however not universal. First and foremost a distribution feeder should be analyzed in the context of proper operation of the proposed method. Conducted tests confirm that models included in simulation software work properly, however, it has to be underlined that tests were carried out in short cable line $370 \mathrm{~m}$ and further tests are planned. It is also planned to develop a criterion for $2 \mathrm{fg}$ fault detection and an expert system, which utilize cable screen earthing current measurement to maximize effectiveness of measuring system.

The proposed algorithm can be combined with distance protection and location algorithms for phase to phase fault location, what allows to combine advantages of both solutions.

Author Contributions: Conceptualization, K.L.; methodology, K.L, J.L.; software, K.L.; validation, K.L., J.L., J.Z.; formal analysis, G.D.; investigation, K.L.; resources, J.Z., J.L., G.D., K.L.; data curation, K.L.; writing-original draft preparation, K.L.; writing—review and editing, K.L., J.L., J.Z.; visualization, K.L.; supervision, J.L., J.Z.; project administration, K.L.; All authors have read and agreed to the published version of the manuscript.

Funding: The research was financed from resources of the Ministry of Science and Higher Education for Statutory Activities No. 0711/SBAD/4410, name of the task: Improvement of Reliability of Supply in Distribution Network.

Conflicts of Interest: The authors declare no conflict of interest.

\section{References}

1. Schütze, A.; Helwig, N.; Schneider, T. Sensors 4.0-Smart sensors and measurement technology enable Industry 4.0. J. Sensors Sens. Syst. 2018, 7, 359-371. [CrossRef]

2. Kim, B.-S.; Kim, K.-I.; Shah, B.; Chow, F.; Kim, K.H. Wireless Sensor Networks for Big Data Systems. Sensors 2019, 19, 1565. [CrossRef] [PubMed]

3. Bouguera, T.; Diouris, J.-F.; Chaillout, J.-J.; Jaouadi, R.; Andrieux, G. Energy Consumption Model for Sensor Nodes Based on LoRa and LoRaWAN. Sensors 2018, 18, 2104. [CrossRef] [PubMed]

4. Lowczowski, K.; Nadolny, Z.; Olejnik, B. Analysis of Cable Screen Currents for Diagnostics Purposes. Energies 2019, 12, 1348. [CrossRef]

5. Lowczowski, K.; Lorenc, J.; Andruszkiewicz, J.; Nadolny, Z.; Zawodniak, J. Novel Earth Fault Protection Algorithm Based on MV Cable Screen Zero Sequence Current Filter. Energies 2019, 12, 3190. [CrossRef]

6. Mauseth, F.; Hammervoll, K.D.; Hvidsten, S. Dielectric properties of service aged medium voltage XLPE cable joints. In Proceedings of the 2010 10th IEEE International Conference on Solid Dielectrics, Potsdam, Germany, 4-9 July 2010; Institute of Electrical and Electronics Engineers (IEEE): New York, NY, USA, 2010; pp. 1-4.

7. Frimpong, E.A.; Okyere, P.Y. A Review of Adaptive Autoreclosure Techniques. Indian J.Comput. Sci. Eng. 2010, 1, 222-228.

8. IntelliRupter PulseCloser Fault Interrupter. Available online: https://www.sandc.com/en/products--services/ products/intellirupter-pulsecloser-fault-interrupter (accessed on 10 January 2020).

9. European Commission. Integration of Variable Distributed Resources in Distribution Networks; Seventh Framework Programme; THEME ENERGY: Bilbao, Spain, 2012.

10. CIRED WG03. Fault Management in Electrical Distribution Systems; VTT Technical Research Centre of Finland: Espoo, Finland, 1999. 
11. Seo, H.-C. New Adaptive Reclosing Technique in Unbalanced Distribution System. Energies 2017, $10,1004$. [CrossRef]

12. Platero, C.; Serrano, J.; Lopez-Toledo, M.; Granizo, R. Influence of High-Speed Train Power Consumption and Arc Fault Resistances on a Novel Ground Fault Location Method for $2 \times 25$ kV Railway Power Supply Systems Influence of High-Speed Train Power Consumption and Arc Fault Resistances on a Novel Ground Fault. Energies 2018, 11, 1601. [CrossRef]

13. Hoppel, W.; Sieluk, W.; Czarnecki, D. Zabezpieczenie podimpedancyjne w terminalach polowych CZIP-PRO dla linii sredniego napięcia. Wiadomosci Elektrotechniczne 2019, 87, 31-36. [CrossRef]

14. Tutvedt, K.A.; Seguin, R.; Kjolle, G.; Simonsen, S.; Hermansen, T.S.; Myhr, I. Smart fault handling in medium-voltagedistribution grids. In Proceedings of the 24th International Conference \& Exhibition on Electricity Distribution, Glasgow, Scotland, 12-15 June 2017.

15. Wurm, M. Earth Fault Distance Localization in Inductive Earthed Networks by means of Distance Protection. In Proceedings of the 21st International Conference on Electricity Distribution, Frankfurt, Germany, 6-9 June 2011.

16. Siemens, Applications for 2005 SIPROTEC Protection Relays; Siemens Aktiengesellschaft: Nuernberg, Germany, 2005.

17. ABB. Distance Protection REF 542plus-Application and Setting Guide; ABB: Vaasa, Finland, 2008.

18. Tshobeni, S. Short Feeder Distance Protection and its Application Limits. In Proceedings of the 19th International Conference on Electricity Distribution, Vienna, Austria, 21-24 May 2007.

19. Tsimtsios, A.M.; Nikolaidis, V.C. Application of distance protection in mixed overhead-underground distribution feeders with distributed generation. J. Eng. 2018, 2018, 950-955. [CrossRef]

20. Jensen, C.; Nanayakkara, O.; Rajapakse, A.; Gudmundsdottir, U.; Bak, C. Online fault location on AC cables in underground transmission systems using sheath currents. Electr. Power Syst. Res. 2014, 115, 74-79. [CrossRef]

21. Bernadić, A.; Leonowicz, Z. Fault location in power networks with mixed feeders using the complex space-phasor and Hilbert-Huang transform. Int. J. Electr. Power Energy Syst. 2012, 42, 208-219. [CrossRef]

22. Rajalakshmi, B.; Kalaivani, L.B.R. Analysis of Partial Discharge in underground cable joints. In Proceedings of the 2015 International Conference on Innovations in Information, Embedded and Communication Systems (ICIIECS), Coimbatore, India, 19-20 March 2015; Institute of Electrical and Electronics Engineers (IEEE): New York, NY, USA, 2015; pp. 1-5.

23. Le, T.D.; Petit, M. An Optimisation algorithm for Earth fault location. In Proceedings of the 24th International Conference on Electricity Distribution, Glasgow, Scotland, 12-15 June 2017.

24. Linčiks, J.; Baranovskis, D. Single Phase Earth Fault Location in the Medium Voltage Distribution Networks. Sci. J. Riga Tech. Univ. Power Electr. Eng. 2009, 25, 13-18. [CrossRef]

25. Farughian, A.; Kumpulainen, L.; Kauhaniemi, K. Earth Fault Location Using Negative Sequence Currents. Energies 2019, 12, 3759. [CrossRef]

26. Carlsson, F.; Etherden, N.; Johansson, A.; Wall, D.; Fogelberg, A.; Lidström, E. Advanced fault location in compensated distribution networks. CIRED Workshop 2016, 114. [CrossRef]

27. Olejnik, B. Skutecznosc Sygnalizatorow Przeplywu Pradu Zwarciowego Podczas Wysokooporowych Zwarc Doziemnych W Sieci Sredniego Napiecia; Poznan University of Technology Publishing House: Poznan, Poland, 2020.

28. Sunil, D.V.; Yadaiah, N. An expert system for fault location in distribution feeder line. In Proceedings of the 2017 International Conference on Energy, Communication, Data Analytics and Soft Computing (ICECDS), Chennai, India, 1-2 August 2017; Institute of Electrical and Electronics Engineers (IEEE): New York, NY, USA, 2017; pp. 2465-2469.

29. Almeida, B.; Louro, M.; Queiroz, M.; Neves, A.; Nunes, H. Improving smart SCADA data analysis with alternative data sources. CIRED-Open Access Proc. J. 2017, 2017, 1223-1226. [CrossRef]

30. Vieira, F.; Santos, P.H.M.; Filho, J.M.C.; Leborgne, R.C.; Leite, M.P. A Voltage-Based Approach for Series High Impedance Fault Detection and Location in Distribution Systems Using Smart Meters. Energies 2019, 12, 3022. [CrossRef]

31. Arrabe, R.G.; Platero, C.A.; Gomez, F.A.; Rebollo, E. Novel Auto-Reclosing Blocking Method for Combined Overhead-Cable Lines in Power Networks. Energies 2016, 9, 964. [CrossRef]

32. Dashti, R.; Salehizadeh, S.M.; Shaker, H.R.; Tahavori, M. Fault Location in Double Circuit Medium Power Distribution Networks Using an Impedance-Based Method. Appl. Sci. 2018, 8, 1034. [CrossRef] 
33. Rahim, M.N.A.; Mokhlis, H.; Abu Bakar, A.H.; Jamian, J.J.; Sukumar, S. Progress on Protection Strategies to Mitigate the Impact of Renewable Distributed Generation on Distribution Systems. Energies 2017, 10, 1864.

34. Joint Working Group IEEE Power and Energy Society. Fault Current Contributions from Wind Plants; Joint Working Group IEEE Power and Energy Society: College Station, TX, USA, 2015; pp. 137-227.

35. Tang, W.-J.; Yang, H.-T. Data Mining and Neural Networks Based Self-Adaptive Protection Strategies for Distribution Systems with DGs and FCLs. Energies 2018, 11, 426. [CrossRef]

36. Kilickiran, H.C.; Akdemir, H.; Sengor, I.; Kekezoglu, B.; Paterakis, N.G. A Non-Standard Characteristic Based Protection Scheme for Distribution Networks. Energies 2018, 11, 1241. [CrossRef]

37. Ates, Y.; Boynuegri, A.R.; Uzunoglu, M.; Nadar, A.; Yumurtacı, R.; Erdinç, O.; Paterakis, N.G.; Catalão, J.P. Adaptive Protection Scheme for a Distribution System Considering Grid-Connected and Islanded Modes of Operation. Energies 2016, 9, 378. [CrossRef]

38. Chul, S.H. Novel Protection Scheme considering Tie Switch Operation in an Open-Loop Distribution System using Wavelet Transform. Energies 2019, 12, 1725.

39. PSCAD 4.6.2 Automation API Documentation 2019. Available online: https://hvdc.ca/knowledge-base/read, article/459/pscad-4-6-2-automation-api-documentation/v (accessed on 10 January 2020).

40. IEEE Std $575^{\mathrm{TM}} 2014$ Guide for Bonding Shields and Sheaths of Single-Conductor Power Cables Rated $5 \mathrm{kV}$ through $500 \mathrm{kV}$. Insul. Cond. IEEE Power Energy Soc. 2014, 1-83.

41. Milovac, P.; Javora, R.; Skendzic, V. Sensor technology in a medium-voltage switchgear for the US market applications. CIRED-Open Access Proc. J. 2017, 2017, 432-435. [CrossRef]

42. Mikronika. Urzadzenia dla Energetyki. Zabezpieczenia firmy Mikronika serii SO-54SR-xxx do zastosowan 2018, 5, 36-39.

43. Bernadic, A.; Anane, Z. Neutral Point Connections in MV Power Networks with Grounding Zigzag Transformers-Analysis And Simulations. J. Energy 2019, 68, 42-48.

44. Megger. Getting Down to Earth A Practical Guide to Earth Resistance Testing; MeterCenter: Chandler, AZ, USA, 2015.

45. Zawodniak, J.; Wielkopolski, S.O. Podstawowe bledy popelniane podczas projektowania i wykonywania uziemien. Autom. Elektr. ZAKLOCENIA 2017, 8, 92-97. [CrossRef]

46. Andruszkiewicz, J.; Lorenc, J.; Łowczowski, K.; Weychan, A.; Zawodniak, J. Energy losses' reduction in metallic screens of MV cable power lines and busbar bridges composed of single-core cables. Ekspolatacja $i$ Niezawodn.-Maint. Reliab. 2019, 22, 15-25. [CrossRef]

47. Todorovski, M.; Ackovski, R. Equivalent Circuit of Single-Core Cable Lines Suitable for Grounding Systems Analysis Under Line-to-Ground Faults. IEEE Trans. Power Deliv. 2013, 29, 751-759. [CrossRef]

48. Liang, Z.; Zhu, G. Analysis of Earth Currents in a Medium-Voltage Distribution Network with Three-Core Cables. In Proceedings of the IEEE Innovative Smart Grid Technologies-Asia, Bangkok, Thailand, 3-6 November 2015.

49. Benato, R.; Sessa, S.D.; Guglielmi, F.; Partal, E.; Tleis, N. Ground Return Current Behaviour in High Voltage Alternating Current Insulated Cables. Energies 2014, 7, 8116-8131. [CrossRef]

50. Viel, E.; Griffiths, H. Fault current distribution in HV cable systems. IEE Proc.-Gener. Transm. Distrib. 2000, 147, 231. [CrossRef]

51. Mangione, S. A Simple Method for Evaluating Ground-Fault Current Transfer at the Transition Station of a Combined Overhead-Cable Line. IEEE Trans. Power Deliv. 2008, 23, 1413-1418. [CrossRef]

52. Jing, L.; Son, D.-H.; Kang, S.-H.; Nam, S.-R. A Novel Protection Method for Single Line-to-Ground Faults in Ungrounded Low-Inertia Microgrids. Energies 2016, 9, 459. [CrossRef]

53. Khakimzyanov, E.; Mustafin, R.; Platonov, P. Method of fault location for double line-to-earth faults in distribution networks. Eng. Sci. Technol. Int. J. 2016, 19, 1668-1671. [CrossRef]

54. Strzalka, J.T.; Wojsznis, T. Zasady wykonywania pomiarow uziemien i oceny wynikow pomiarow. Biul. SEP 2003, 20, 1-15.

55. Popovic, L.M. Comparative analysis of grounding systems formed by MV cable lines with either uninsulated or insulated metal sheath(s). Electr. Power Syst. Res. 2011, 81, 393-399. [CrossRef]

56. Tele-Fonika Kable S.A. Kable i przewody elektroenergetyczne; Tele-Fonika Kable S.A: Cracow, Poland, 2019; pp. 276-310. 
57. ScottishPower, ScottishPower Distribution Cables \& Equipment. Metal Theft. Available online: https: //www.spenergynetworks.co.uk/userfiles/file/ScottishPower_cables_equipment_metal_theft.pdf (accessed on 26 February 2016).

58. Strunz, K.; Abbasi, E.; Abbey, C.; Andrieu, C.; Gao, F.; Gaunt, T. Benchmark Systems for Network Integration of Renewable and Distributed Energy Resources. Cigre Task Force C 2014, 6, 78.

59. Wannous, K.; Toman, P. Evaluation of Harmonics Impact on Digital Relays. Energies 2018, 11, 893. [CrossRef]

60. Lorenc, J. Admitancyjne Zabezpieczenia Ziemnozwarciowe; Wydawnictwo Politechniki Poznanskiej: Poznan, Poland, 2007.

61. Mugala, G. High Frequency Characteristics of Medium Voltage XLPE Power Cables. KTH Electr. Eng. 2005, $17,93$.

62. Jajczyk, J.; Kasprzyk, L. The Use of Coupled Temperature and Electromagnetic Fields in Optimization Problems. In Proceedings of the 6th IASME/WSEAS International Conference on Heat Transfer, Thermal Engineering and Environment, Rhodes, Greece, 20-22 August 2008.

(C) 2020 by the authors. Licensee MDPI, Basel, Switzerland. This article is an open access article distributed under the terms and conditions of the Creative Commons Attribution (CC BY) license (http://creativecommons.org/licenses/by/4.0/). 